Sheffield

Hallam

Centre for

University

Regional Economic

and Social Research

Evaluation of Heritage Lottery Fund's First World War Centenary Activity: Year 1 report July 2015
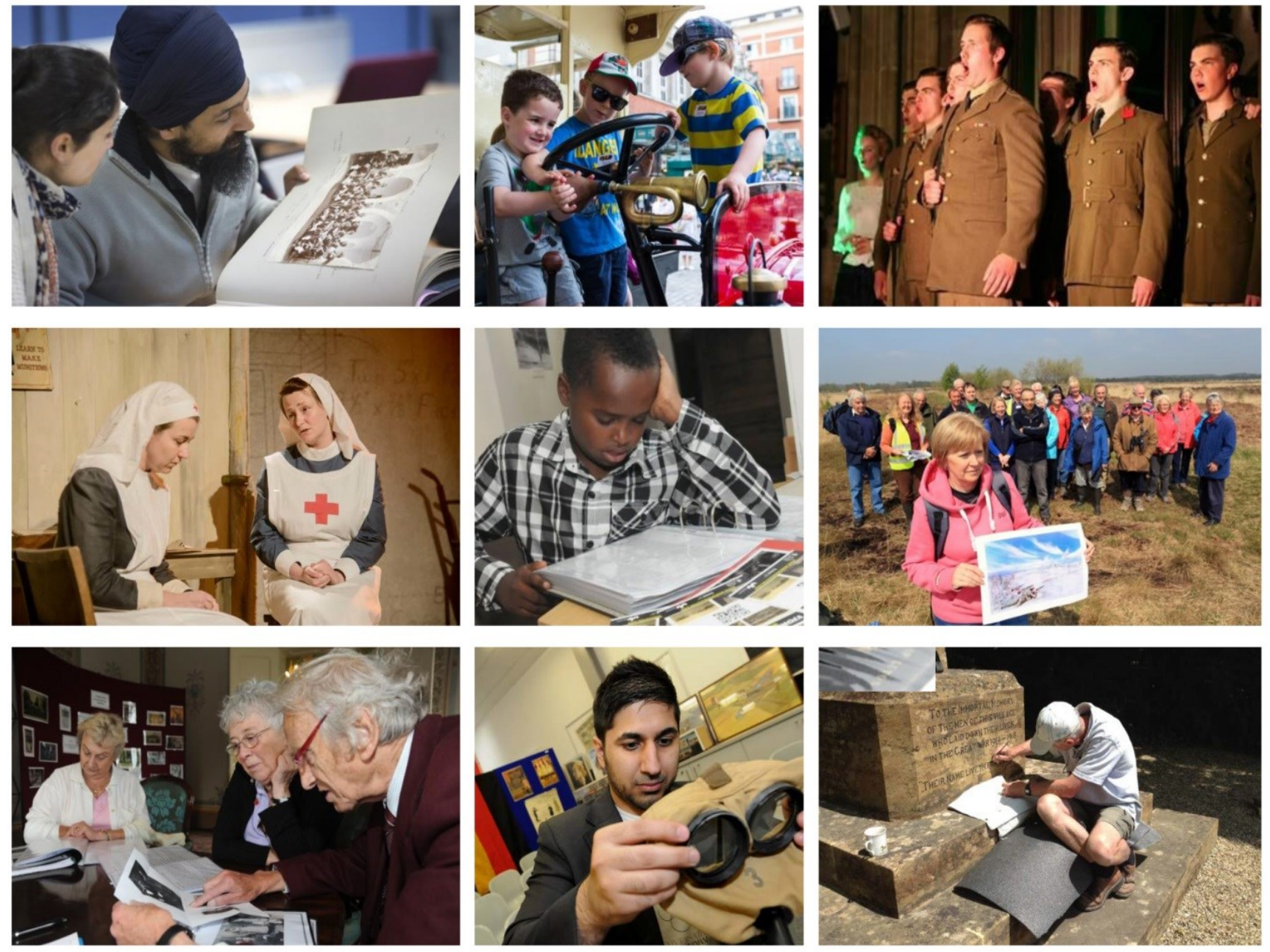


\section{Evaluation of Heritage Lottery Fund's First World War Centenary Activity: Year 1 report}

A report to the Heritage Lottery Fund

\section{Authors:}

Nadia Bashir

Ellen Bennett

Chris Dayson

Will Eadson

Elizabeth Sanderson

Centre for Regional Economic and Social Research (CRESR)

Sheffield Hallam University

July 2015 


\section{Acknowledgements}

Many thanks are due to all who contributed to the study by taking part in interviews and completing the surveys; to Anna Jarvis, Karen Brookfield, Tim Killick and Amelia Robinson at HLF; and to Jess Bamonte, Emma Smith, Lou South and Sarah Ward for invaluable administrative support at CRESR. 


\section{Contents}

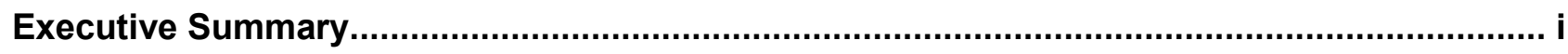

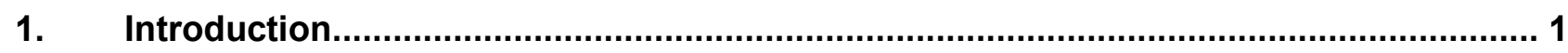

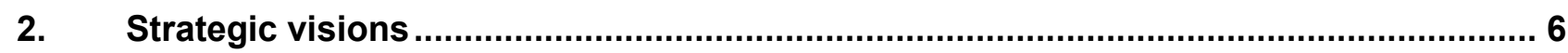

3. What has happened and who is involved in Centenary activities? ............................11

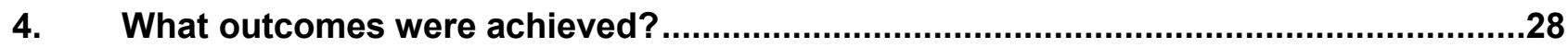

5. What progress has been made on HLF's Centenary aims? ........................................46

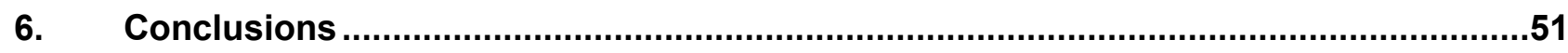

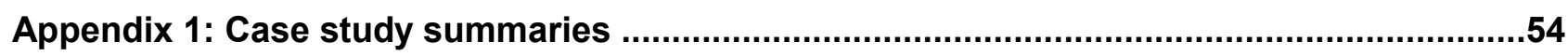

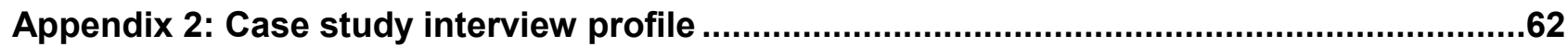




\section{Executive Summary}

\section{Introduction}

The Centre for Regional Economic and Social Research (CRESR), Sheffield Hallam University was appointed by the Heritage Lottery Fund (HLF) to conduct an evaluation of the extent to which its aims for the First World War Centenary have been met across the span of the commemoration period, from 2014 to 2019.

As part of the commemoration of the Centenary of the First World War (FWW), HLF are undertaking a range of activities through both grant-making and working with Government on the UK-wide Centenary programme.

Grants of $£ 3,000$ upwards are being provided for FWW Centenary projects through a number of programmes covering a range of project sizes. The majority of projects so far have been funded through the FWW: Then and Now programme, which was launched in May 2013 and provides grants of up to $£ 10,000$.

The two broad aims of HLF's FWW Centenary-related activity are:

\section{To fund projects which focus on the heritage of the First World War and collectively:}

- create a greater understanding of the First World War and its impact on the range of communities in the UK;

- $\quad$ encourage a broad range of perspectives and interpretations of the First World War and its impacts;

- $\quad$ enable young people to take an active part in the First World War Centenary commemorations;

- leave a UK-wide legacy of First World War community heritage to mark the Centenary;

- increase the capacity of community organisations to engage with heritage, and to raise the profile of community heritage.

2. To use the Centenary projects that HLF funds to communicate the value of heritage, the impact of our funding and the role of HLF.

\section{About the evaluation}

The evaluation focuses on HLF's grant-making activity, covering the first set of aims outlined above.

In assessing success against the aims of the activities as a whole, the evaluation also works to HLF's broader outcomes framework, which focuses on three outcome areas:

- $\quad$ Outcomes for heritage: following HLF investment, heritage will be better managed; in better condition; better interpreted and explained; and identified and recorded. 
- Outcomes for people: following HLF investment, people will have learnt about heritage; developed skills; changed their attitudes and/or behaviour; had an enjoyable experience; and volunteered time.

- Outcomes for communities: following HLF investment, environmental impacts will be reduced; more people, and a wider range of people will have engaged with heritage; organisations will be more resilient; local economies will be boosted; and local areas and communities will be better places to live, work or visit.

In year 1 , the evaluation included the following sets of activities:

- $\quad$ interviews with six internal and external stakeholders;

- review of grant data and project material (for instance HLF application forms, HLF case material and projects' internal evaluations);

- $\quad$ surveys of grant recipients and project participants;

- in-depth qualitative case studies of selected projects.

This report is based on the first year of evaluation activity and data is being collected evenly over a number of years rather than an intensive period of collection at any one point. As a result response numbers are often quite low at this stage, especially for the participant survey. It is important to make clear that, as a result, any presented findings are only indicative.

\section{What has happened in Centenary activities?}

Between April 2010 and May 2015, HLF awarded over $£ 70$ million to more than 1,200 FWW Centenary projects.

Funding for projects was spread broadly evenly across the UK, with some small outliers: London and Northern Ireland received slightly more funding per capita than other regions, largely owing to large grants for the Imperial War Museum and HMS Caroline respectively; and the North East received funding for a slightly greater number of projects per capita than other regions.

Project size varied significantly, although the great majority of grants were small: 75 per cent were for $£ 10,000$ or less and 12 per cent were for between $£ 10,000$ and $£ 50,000$. Although only a few very large grants of $£ 1$ million or more were awarded, these accounted for more than half (57 per cent) of the value of grants awarded. The wide range of grant size awarded - from $£ 3,000$ to $£ 12.4$ million - highlights the breadth and complexity of FWW Centenary projects funded by HLF.

The Grant Recipient Survey asked respondents about the conservation and other heritage-related activities undertaken by projects. Answers highlighted the central role of collecting historical source material such as documents, photographs, oral histories and artefacts in a large majority of funded projects (more than nine in ten). Similarly, activities that involve cataloguing (including digitisation) archive material and conserving archives and artefacts have been an important focus of projects so far.

Over two-thirds (69 per cent) of projects produced a website, and over half produced a display or temporary exhibition. Film and performance were also an important output of many projects, with 50 per cent producing a film and 40 per cent putting on a performance of some kind. Fewer projects had produced permanent exhibitions, with fewer than one in ten creating a permanent exhibition in a community venue or a permanent exhibition in a museum, heritage centre, gallery or library.

Grant Recipients were also asked about the activities being carried out as part of their projects. Similar to responses regarding First World War themes, responses highlighted the local focus of the majority of projects. More than nine in ten projects said they held community events and participants in community events $(40,079)$ accounted for more than half of all participants in 
specific types of activity. Other prominent activities included talks by experts (more than half of projects), visits and outreach with schools and colleges (around half of projects) and outreach sessions in community venues (around two-fifths of projects).

\section{Who was involved in Centenary activities?}

Overall, the 64 funded projects that responded to the Grant Recipient Survey reported having 768,578 participants.: 1 This figure includes a number of projects that were already complete (43) and a number of longer term projects that had been up and running for at least 12 months (21).

It should be noted that projects lasting more than one year contributed many more participants (93 per cent; 34,343 per project) than completed projects ( 7 per cent; 1,346 per project). This is because longer term projects tend to be larger, and based in visitor attractions whereas completed projects tended to be short in duration and have more of a community focus. A banded breakdown of the number of participants is provided in Table 3.5 to illustrate this point in more detail. This shows how projects ranged widely in their 'reach', with a relatively even split across different bands of participant numbers between 'less than 100' and up to 5,000 participants. This should be expected in line with the variation in project funding, scope, focus and outputs.

Looking at the demographics of participants, participation was evenly distributed by gender but there were some significant variations according to age and ethnicity. More than three-quarters of participants were adults aged over 26 and there was a significant number - more than a third aged 65 or over. By contrast 18 per cent of participants were of school or college age. Young people aged 17-25 were particularly underrepresented relative to the UK population. In terms of ethnicity, almost nine in 10 were White British with far fewer from black. Asian and minority ethnic communities.

\section{Volunteering}

Overall, 95 per cent of respondents to the Grant Recipient Survey reported having used volunteers in their FWW Centenary project. This amounted to almost 2,600 people providing more than 16,000 hours of their time willingly and free-of-charge. Volunteers undertook a variety of roles and in many cases were central to the running of projects. The most frequently identified roles were directly related to the provision of activities: three-quarters of respondents said volunteers coordinated and led activities or were involved in research and archival work while almost twothirds devised and delivered work with the public; more than half did this for schools and almost a third did so for young people outside school.

\section{Why did projects and participants get involved with Centenary activities?}

Respondents to both the Grant Recipient and Participant surveys were asked about their motivations for taking part. Looking first at the Grant Recipients, almost all of the projects referred to the importance of doing something to mark the Centenary in and of itself. Another significant theme was the use of the Centenary as a theme for existing or planned activities. Other prominent themes included:

- following-up from a previous community, heritage or FWW project

- a desire to engage young people with FWW heritage

- a desire to engage the local community with FWW heritage

- wanting to conduct repairs to war memorials

- $\quad$ personal interest in a subject related to the FWW Centenary

\footnotetext{
${ }^{1}$ Note that this figure and subsequent analyses excludes the Imperial War Museum First World War Galleries, which had over one million visitors in 2014/15.
} 
Respondents to the Participant survey were also asked why they decided to take part in FWW Centenary activities, and were asked to choose from a list of options. Over half (20 out of 34 respondents) of participants took part to learn more about the FWW in the local area, and also out of a desire to personally commemorate the Centenary (18 out of 34). The latter chimes with the motivations given by Grant Recipients about the importance of marking the Centenary in itself.

\section{What outcomes were achieved?}

The evaluation explored the extent and ways in which FWW Centenary activities have achieved different types of outcome, and specifically those identified within the HLF outcomes framework. Some outcome areas are better evidenced than others at this stage. In particular, there is stronger evidence of people outcomes than other areas. This is partly due to the developing dataset, but is also owing to the nature of projects, which have tended to exhibit strong people outcomes but fewer heritage outcomes.

\section{Outcomes for heritage}

The strength of evidence was mixed across the set of heritage outcomes, but key points include:

- $\quad$ on the outcome, heritage will be in better condition, 32 per cent of Grant Recipient Survey respondents reported that their project had improved the physical state of FWW heritage, with 10 per cent regarding it as their most important outcome.

- the outcome heritage will be identified was viewed as an important outcome for most projects, with 77 per cent of projects stating that they had achieved this outcome and 39 per cent marking it out as their most important outcome

- $\quad$ FWW Centenary funding is being used to better interpret and explain heritage through a wide range of methods, with the possibility for projects of all sizes to engage in different activities to meet this outcome.

\section{Outcomes for people}

Outcomes for people were the most well-evidenced in the first year of the evaluation. Key findings include:

- 48 per cent of projects aimed to improve people's skills, so that they are better able to look after and manage heritage, although only five per cent included this as a main or most important aim of their project.

- In meeting the outcome area people will have changed their attitudes/behaviour, 81 per cent of Grant Recipient Survey respondents felt that their project had led to a change in the way the people thought about the FWW. The majority of participants said that their engagement with the FWW Centenary activities had 'challenged' them and had been thought-provoking.

- $\quad$ The outcome people will have learned about heritage was well evidenced. This was a project outcome for 98 per cent of respondents to the Grant Recipient Survey, 84 per cent of whom said it was one of the most important outcomes. Participants reported gains in their knowledge about the FWW across a range of themes.

- Respondents enjoyed taking part in HLF funded activities. When asked to rate the level of enjoyment derived from taking part on a scale of 1-10, all participant respondents gave a response of 5 or above with 42 out of 48 respondents giving a score of 9 or 10 .

- $\quad$ Looking at the outcome, people will have volunteered time, as noted above, 95 per cent of respondents to the Grant Recipient Survey said that their projects involved volunteers. This amounted to almost 2,600 people providing more than 16,000 hours of their time willingly and free-of-charge. 
- The evaluation also found evidence of achievement against two important additional people outcomes that are not captured in HLF's outcomes framework: mental wellbeing, and emotional development/enrichment of participants.

\section{Outcomes for communities}

Grant recipients were able to provide some evidence across each of the outcomes areas, with the exception of reduced environmental impacts, which was not covered in evaluation questions. Key findings include:

- In terms of engaging more people and a wider range of people, 84 per cent of Grant Recipient Survey respondents said engaging more people was an outcome of their project. Engaging a wider range of people was less well evidenced, although around two-fifths (39 per cent) of Grant Recipient Survey respondents said that they had achieved this outcome. Only five per cent of respondents felt that this was one of the main or most important outcomes of their project.

- $\quad$ Thinking about making your local area a better place to live, work or visit, 19 out of 30 Participant Survey respondents gave a response of eight or more when asked to rate the impact projects had on their local community on a scale of 1-10. This was borne out in case studies, with the Brierfield Our First World War One project being particularly successful in helping to improve community cohesion in their local area.

\section{Progress against Centenary activity aims}

The evaluation also made an assessment of progress against HLF's FWW Centenary aims as set out above. These can be summarised as follows:

- create a greater understanding of the First World War and its impact on the range of communities in the UK: there was good evidence of improved understanding of the FWW and its impact in broad terms, although there is more work required to understand the extent to which 'the range of communities in the UK' are covered by funded activities.

- $\quad$ encourage a broad range of perspectives and interpretations of the First World War and its impacts: there was evidence that FWW Centenary activities are allowing individuals to develop understanding of many different elements of the FWW, although there is potentially a challenge for HLF to encourage projects to explore a wider range of stories across the suite of projects.

- enable young people to take an active part in the First World War Centenary commemorations: Grant Recipient Survey responses suggest that young people aged 11-25 were slightly underrepresented relative to the UK population. There was, however, good evidence of projects seeking to engage with young people through schools.

- leave a UK-wide legacy of First World War community heritage to mark the Centenary: An important way in which HLF are seeking to do this is by including project websites in the British Library UK Web Archive. The use of Historypin to document a project might also be seen as a means of creating a legacy of projects, and 42 per cent of projects that responded to the Grant Recipient Survey had done this.

- $\quad$ increase the capacity of community organisations to engage with heritage, and to raise the profile of community heritage: there is clear evidence that HLF funding has increased capacity across a number of domains and 100 per cent of Grant Recipient Survey respondents felt that HLF funding had positively impacted on the capacity of their organisation in some way

Overall there was evidence of progress against each aim, with some scope for further work on understanding the extent to which the range of communities across the UK were being reached and the range of perspectives being covered by projects. 


\section{Conclusions}

The first year of the evaluation of HLF's FWW Centenary activity has highlighted a number of key successes. Demand for funding has been extremely strong, leading to significant funded activity at the local level, and large numbers of people have engaged with projects. HLF funding is having a clear impact on the capacity of organisations to deliver projects and there is also some evidence of impact on longer-term capacity. As a suite of activity, there is evidence of outcomes across almost all outcome areas, and people outcomes are particularly well evidenced, particularly learning about heritage.

A number of challenges for projects and HLF also emerged, including engaging a wider audience with FWW Centenary activities, particularly the 18-25 age group, and for HLF to encourage more projects to go beyond local history to incorporate a broader range of perspectives on the FWW.

The evaluation will seek to build the evidence base over the next year in order to provide a more robust analysis of the achievements of HLF Centenary activity. 


\section{Introduction}

As part of the 2014-18 commemoration of the Centenary of the First World War (FWW), the Heritage Lottery Fund (HLF) is undertaking a range of activities through both grant-making and working with Government on the UK-wide Centenary programme.

Grants of $£ 3,000$ upwards are being provided for FWW Centenary projects through a number of programmes, including:

- $\quad$ First World War: Then and Now, which funds projects up to $£ 10,000$ which explore, conserve and share the heritage of the FWW

- Our Heritage, which provides grants of $£ 10,000-£ 100,000$ for projects which focus on any type of heritage

- $\quad$ Young Roots, providing $£ 10,000-£ 50,000$ for projects led by young people, and which are delivered in partnership between a youth organisation and a heritage organisation;

- Heritage Grants, which provide grants of more than $£ 100,000$ for projects which focus on any type of heritage.

In excess of 1,000 FWW Centenary projects have been funded since April 2010. This includes over 800 projects funded through the FWW: Then and Now programme (as of March 2015).

The two broad aims of HLF's FWW Centenary-related activity are:

1. To fund projects which focus on the heritage of the First World War and collectively:

- create a greater understanding of the First World War and its impact on the range of communities in the UK;

- encourage a broad range of perspectives and interpretations of the First World War and its impacts;

- enable young people to take an active part in the First World War Centenary commemorations;

- leave a UK-wide legacy of First World War community heritage to mark the Centenary;

- $\quad$ increase the capacity of community organisations to engage with heritage, and to raise the profile of community heritage.

2. To use the Centenary projects that HLF funds to communicate the value of heritage, the impact of our funding and the role of HLF. 


\subsection{The evaluation}

The Centre for Regional Economic and Social Research (CRESR), Sheffield Hallam University was appointed by HLF to conduct an evaluation of the extent to which the aims set out above have been met, across the range of FWW Centenary activities taking place, and across the span of the commemoration period, from 2014 to 2019. The evaluation focuses on its grant-making activity, covering the first set of aims outlined above.

In assessing success against the aims of the activity as a whole, the evaluation also works to HLF's broader outcomes framework, which focuses on three outcome areas:

- Outcomes for heritage: following HLF investment, heritage will be better managed; in better condition; better interpreted and explained; and identified and recorded.

- $\quad$ Outcomes for people: following HLF investment, people will have learnt about heritage; developed skills; changed their attitudes and/or behaviour; had an enjoyable experience; and volunteered time.

- Outcomes for communities: following HLF investment environmental impacts will be reduced; more people, and a wider range of people will have engaged with heritage; organisations will be more resilient; local economies will be boosted; and local areas and communities will be a better place to live, work or visit.

Accordingly this report devotes time to both assessing the extent to which outcomes have been achieved and to evaluating progress made on aims.

This report is based on the first year of evaluation activity and data is being collected evenly over a number of years rather than an intensive period of collection at any one point. As a result response numbers are often quite low at this stage, especially for the participant survey. It is important to make clear that, as a result, any presented findings are only indicative. In particular, discussion of survey data for participants is based on a small number of responses. We have included this data where possible to provide a sense of initial trends or findings, but in places we have been more reliant on case study material to fill in gaps in the evidence than would normally be the case. As the dataset grows from Year 2 onwards this issue will diminish.

\subsection{Evaluation approach}

The evaluation takes a 'logic chain' approach to underpin analysis. This approach focuses on mapping the development of the project 'theory' (assumptions and rationales behind the programme and its operation) through to programme inputs (financial and staff expertise) activities (e.g. grant-making,), outputs (events/activities taking place, people participating in activities) and outcomes (measurable change for individuals, heritage and - potentially - communities). Tracking the theory of change 'logic chain' requires assessment at three 'levels' of operation:

1. Strategic direction (HLF plus other key stakeholders);

2. On-the-ground delivery ( project leads);

3. Participation (those who take part in activities/events/projects). 
This is achieved through the following sets of activities:

- interviews with six internal and external stakeholders;

- review of grant data and project material (for instance HLF application forms, HLF case material and projects' internal evaluations) ;

- $\quad$ surveys of grant recipients and project participants;

- in-depth qualitative case studies of selected projects.

A yearly cycle of evaluation activity will be undertaken, following a broadly similar process each year.

\section{Grant Recipient Survey}

The online Grant Recipient Survey aims to capture the perceptions, experiences and achievements of groups and organisations in receipt of funding from HLF for First World War Centenary activities. The survey invitation is sent to grant recipients by the evaluation team shortly after their project has been completed and asked to provide information covering the whole period the funding was provided for. A small number of larger projects (lasting more than a year) are sent the survey on an annual basis and asked to provide information covering the past 12 months.

The survey commenced in January 2015 and will be undertaken on a rolling basis throughout the evaluation. This report is based on data from that point until the end of February 2015. During that period 171 surveys were sent out (including 58 annual surveys) and 69 responses (23 annual survey responses) were received: a response rate of 40 per cent. It is these responses on which the analysis presented in this report is based.

Survey data collection will be ongoing for the duration of the evaluation and subsequent reports will provide aggregate and annualised analysis of the responses received. In addition, and as the number of responses increases, more in depth thematic analysis of outputs and outcomes will be undertaken.

A version of the survey can be viewed via this link:

http://www.shu.ac.uk/research/cresr/sites/shu.ac.uk/files/hlf-grant-recipientsurvey.pdf

\section{Participant Survey}

The online Participant Survey aims to capture the views, experiences and outcomes of people who have participated in HLF funded First World War Centenary activities. Participants include project volunteers, people who have visited projects or taken in part in activities, and people who have received training. Possible participants are identified by funded projects that collect email addresses and pass them on to the evaluation team. Once this information has been provided an email invitation is sent to participants asking them to complete the survey.

The survey commenced in January 2015 and will be undertaken on a rolling basis throughout the evaluation. This report is based on data received up to 11 March 2015. So far 198 surveys have been sent out and 49 responses have been received: a response rate of 25 per cent. It is these responses on which the analysis presented in this report is based. Again, this is a small dataset at this stage and as such participant survey analysis presents purely indicative findings. 
A version of the survey can be viewed via this link:

http://www.shu.ac.uk/research/cresr/sites/shu.ac.uk/files/hlf-participant-survey.pdf

\section{Case studies}

As part of the evaluation a series of in-depth project case studies will be undertaken each year, up to a total of 20 case studies over the period. In Year 1 the evaluation included five case studies: these are briefly outlined in Table 1.1 below. More detail on these projects can be found in the case study summaries in Appendix 1.

Table 1.1: Case studies

\begin{tabular}{|c|c|c|}
\hline Project & Location & Description \\
\hline $\begin{array}{l}\text { Our World } \\
\text { War One }\end{array}$ & $\begin{array}{l}\text { Brierfield, } \\
\text { Nelson, North } \\
\text { West }\end{array}$ & $\begin{array}{l}\text { A range of activities working with young people to conduct a } \\
\text { research project and engage the local community in relation } \\
\text { to the role of the Indian Army in the FWW }\end{array}$ \\
\hline $\begin{array}{l}\text { Flintshire } \\
\text { War } \\
\text { Memorials }\end{array}$ & $\begin{array}{l}\text { Flintshire, } \\
\text { Wales }\end{array}$ & $\begin{array}{l}\text { A one-year project to research the stories of individuals } \\
\text { named on war memorials and tell their stories on a website. } \\
\text { The project is volunteer-led, and involves } 24 \text { volunteers } \\
\text { undertaking research on different memorials, and writing } \\
\text { narrative for the website. }\end{array}$ \\
\hline $\begin{array}{l}\text { Somerset } \\
\text { Remembers }\end{array}$ & $\begin{array}{l}\text { Taunton, } \\
\text { South West }\end{array}$ & $\begin{array}{l}\text { Exploration of the impact and long-term legacy of the FWW } \\
\text { on the county of Somerset through a programme of } \\
\text { activities and events, including; a temporary exhibition at } \\
\text { the Museum of Somerset; a digitised collection of FWW } \\
\text { materials for local touring exhibitions; an Online Community } \\
\text { Archive; the contribution of schools, community groups, and } \\
\text { individuals, to an evolving archive of information; a project } \\
\text { website; a learning area with interpretation materials. }\end{array}$ \\
\hline $\begin{array}{l}\text { A War } \\
\text { Unheard }\end{array}$ & $\begin{array}{l}\text { Inverness, } \\
\text { Scotland }\end{array}$ & $\begin{array}{l}\text { Young people researching their family histories of the First } \\
\text { and Second World Wars and present day wars as well as } \\
\text { unheard stories from their local areas. This research was } \\
\text { then used to create a performance for a public audience. }\end{array}$ \\
\hline $\begin{array}{l}\text { On The } \\
\text { Brink }\end{array}$ & $\begin{array}{l}\text { Ballymena, } \\
\text { Northern } \\
\text { Ireland }\end{array}$ & $\begin{array}{l}\text { A three-year project exploring the impact of the FWW, the } \\
\text { Battle of the Somme and the Easter Rising. A particular } \\
\text { focus of the project is supporting people (volunteers, those } \\
\text { who take part in workshops as well as visitors viewing } \\
\text { displays) to develop a broad perspective on historical } \\
\text { events, and understand how events are interconnected. } \\
\text { The project seeks to challenge perceptions and support } \\
\text { learning. }\end{array}$ \\
\hline
\end{tabular}

\subsection{Report structure}

This report is the first of six annual reports covering each year of the evaluation, culminating with a final synthesis report in 2019. The report begins in Chapter 2 with a brief discussion of the 'strategic fit' of the FWW Centenary activity with HLF's priorities and with wider governmental goals. This is followed by a short outline of the 'theory of change' behind the FWW Centenary activity and the development of a basic logic model for understanding the intended impact of activities. Chapter 3 then looks at the composition of activities, using data collected from the first year of the grant-recipient survey and HLF's grant award information. This is then taken forward in Chapter 4 to consider the extent to which projects' activities have fulfilled outcomes across HLF's outcomes framework, before moving on to Chapter 5, which 
brings together the findings to summarise progress against the FWW Centenary activity aims. Chapter 6 then provides a short set of conclusions marking out key successes and challenges faced across the suite of activity, and next steps for the evaluation. 


\section{Strategic visions}

This chapter briefly outlines the background to the HLF FWW Centenary programme and its 'strategic fit', before developing a theory of change-based logic model for understanding the intended outcomes for the suite of activities funded by HLF grants. This chapter draws on interviews with six HLF internal and external stakeholders alongside HLF programme documentation.

\subsection{Background to the HLF FWW Centenary activity}

From early 2011 onwards, HLF engaged in both internal and external discussions to develop a programme of activity relating to the First World War Centenary. For HLF internal stakeholders, it was important that the organisation was a part of the wider Centenary programme as the main funder of heritage projects in the UK. As one internal stakeholder explained:

"It's very clear that there's a huge public appetite for doing something around the centenary and I think as the main heritage funder in the UK it would be letting the side down if we weren't providing the means for people to do that." (Internal Stakeholder)

Following on from discussions with other key partners as part of a government planning group, on $11^{\text {th }}$ October 2012, the Prime Minister announced a broad set of FWW Centenary activity, including government-funded activities and an HLF-funded programme of small community grants (which became First World War: Then and Now). HLF initially allocated at least $£ 6$ million over 6 years to this programme, alongside promoting opportunities through its existing open grants programmes, outlined in the introduction to this report. The First World War: Then and Now (hereafter Then and Now) programme was launched in May 2013.

\subsection{Strategic fit}

Funding for FWW activity has a very clear fit with HLF's wider strategic plan and vision of making "a lasting difference for heritage and people". In particular the Then and Now funding stream continues a commitment in the strategic plan to make heritage more accessible to smaller groups and those that might not have previously applied for funding. It also maps well across onto HLF's corporate objectives, particularly with regard to distributing funding and making the case for the value of heritage. Further to this, the FWW Centenary activity has been embedded across the organisation, with each of the HLF's 12 regional teams having a FWW 'representative'.

It was also well-matched to governmental priorities, and HLF were deeply engaged with the UK government's planning for the Centenary through participation in the government's Centenary planning committee: HLF were considered as the key partner for stimulating community-level activity. In a statement made at the launch of the Then and Now programme, then Minister for Culture, Maria Miller spelled out the importance of HLF's funding: 
It is completely right that we mark the Centenary of the First World War with a national programme capturing our national spirit and saying something about who we are as a people. But what we do also needs to help create an enduring cultural and educational legacy for communities. The HLF grant programme announced today will play a big part in this, and builds on the substantial investment they have already made towards the Centenary. ${ }^{2}$

Similarly, HLF's work was seen by stakeholders to fit well with the broader heritage sector, especially the strategies and programmes developed alongside HLF's work by the First World War Centenary Partnership, led by the Imperial War Museum (IWM) and the Arts and Humanities Research Council (AHRC).

\subsection{The theory of change behind HLF's FWW Centenary activity}

Moving on from consideration of the background of the FWW Centenary activity and its fit with governmental and other organisations' priorities, it is important next to consider the rationale for the programme in terms of its intended outcomes. As noted in Section 1 above, this evaluation uses a logic chain approach based on developing a 'theory of change' for the activity. This considers the intended 'pathway' for an intervention from inputs through to outcomes, based on key assumptions or hypotheses about how the intervention was designed to work. These assumptions and the related logic chain have been constructed by the evaluation team, drawing from the stakeholder interviews and HLF documentation. In other words, these were not necessarily always explicitly considered by HLF in setting out their rationale for undertaking the FWW Centenary activity: rather they have been 'retrofitted' by the evaluation team in order to create a model for evaluating the success of the activity against 'what we might expect'.

In the case of funding for FWW activity, the intervention can be understood by referring to a number of assumptions. These include the following:

1. Funding will lead to outcomes captured by HLF's outcome areas (and other possible additional or wider outcomes) and meet HLF's FWW Centenary aims.

2. Outcomes will not be achieved (or will be to a lesser extent) without funding.

3. There is particular value in funding FWW activities at this time.

4. Promoting FWW activities will catalyse heritage activity more generally.

These are briefly outlined in turn, below.

\subsubsection{Funding activities will lead to a range of outcomes}

The central assumption was that providing funding for activities would lead to a range of different outcomes, in particular those measurable through HLF's outcome framework (14 outcomes for heritage, people and communities). This was discussed in stakeholder interviews, but more generally it follows that HLF will fund activities that will contribute to its outcomes framework. This also included meeting a set of aims for HLF's FWW Centenary funding (as outlined above). This is central to the 'logic chain' outlined below (Section 2.4.2): the idea that funding projects leads to activities that in turn generate outcomes. A key element of this is in determining an appropriate set of outcomes for projects and for the aims for the FWW activity as a whole. Internal and external stakeholders were agreed that these were appropriate and achievable aims, although there was some discussion among stakeholders

\footnotetext{
${ }^{2}$ HLF (2013) "HLF's new First World War programme opens". Accessed online at: http://www.hlf.org.uk/aboutus/media-centre/press-releases/hlf\%E2\%80\%99s-new-first-world-war-programme-opens
} 
about whether other aims (and underpinning outcomes) might have been included, such as:

- $\quad$ quality of life (people);

- community cohesion (community);

- intergenerational connections (community).

It was felt by stakeholders in the case of the first two possibilities that this was asking too much of the suite of activities; and although they might contribute to outcomes that improve quality of life or community cohesion (see Chapter 4) it would be hard to capture these outcomes. Intergenerational cohesion was seen as an important goal, but equally there was a concern that including this as an aim would potentially shape the focus of activities towards oral histories, which could be problematic given the lack of direct lived experience of the FWW.

There are two potential overarching risks here: that demand for funding was insufficient for activities to collectively meet outcomes and aims; and that funding was provided to projects that do not adequately produce outcomes or meet HLF's aims for the activities.

\subsubsection{Outcomes will not be achieved (or will be to a lesser degree) without HLF funding}

Linked to the logic chain was the assumption that, without HLF funding, outcomes would not be achieved, or at least to a lesser extent. Again, this was discussed in stakeholder interviews, and follows a more general logic that funding would not be provided if it was not considered to have a good level of additionality. For instance, projects that did go ahead without funding would achieve reduced outcomes:

"Some things undoubtedly would [go ahead], so people would have probably sought to restore their war memorial but they probably would have just done the conservation work and they might not have involved a wider group of people, they might not have thought about it so deeply, they might not have made some lasting things, books, pamphlets, films ... [and] lots and lots of projects would not have happened." (Internal Stakeholder)

Specifically, this assumed that funding for FWW-related events was a better means of stimulating a wider range of outcomes than promoting funding for a different subject matter. There was also an assumption here that the popularity of the FWW Centenary would tap into heritage potential that would not otherwise have been realised. This was a point of discussion for a majority of stakeholders, with a consensus emerging that the popular appeal of the FWW Centenary and the wider suite of government-led and cultural activities taking place across the country further fuelled this.

\subsubsection{The value of funding FWW activity during the Centenary}

An important consideration was the 'legacy' of the FWW projects and this was explicitly marked out in the aims of the FWW Centenary activity. There was an underlying feeling of responsibility to future generations: "that this shouldn't be a moment in which somebody would look back later and say 'but they didn't make a good record of it and they let it all go'" (Internal Stakeholder). This was also about ensuring that the intrinsic value of FWW-related heritage projects was balanced with contemporary relevance, and achieving outcomes for individuals and communities. This cut across decision-making for funding from the first planning stages, for instance in deliberating about the name for Then and Now: 
"We spent quite a lot of time discussing the title [of First World War: Then and Now], very consciously chose the title to be reflective of wanting people to think about the past but also think about its implications today, the legacy, the impact of the war" (Internal Stakeholder)

More broadly this was about harnessing the popular appeal of the FWW for meeting HLF and wider societal aims. In particular the FWW offered an opportunity to engage people in heritage through a subject that most people had some kind of personal familial connection with: "can you move from the personal to the local ... from national to international [and so on]" (Internal Stakeholder). This is an important point for this evaluation: can funding of 'grassroots' projects lead to activities and outcomes that move beyond a consideration of the immediate story of a family member or local resident to something that 'means something' to and impacts upon people and communities in different ways?

In this regard the Then and Now programme was seen as an important mechanism for 'making the most' of the Centenary. The programme was launched shortly after the successful completion of a community grants programme, All Our Stories, which had shown the potential value of small grant schemes. Previous commemorative anniversaries, such as the Bicentenary of the abolition of the slave trade in 2007 had been promoted through open grants programmes, which had also seen a range of different types of organisation engage with the Centenary: as a result the FWW Centenary activity was designed to incorporate both approaches.

The rationale was to allow space for a range of different sized projects to access funding. Larger projects were funded through open grants programmes, which meant that they were 'in competition' with projects that were not FWW-related, but this was seen as the best way to ensure that a range of different types of projects could be funded:

"If we'd set a ring-fenced budget, well we've already proved that however big it was it wouldn't have been big enough and it would never have accommodated, for example, HMS Caroline at £12 million, York Castle at two and a bit, we'd always have risked squeezing out the little ones. So I think the challenge of balancing big First World War projects against a big other project is better than having to decide." (Internal Stakeholder)

\subsubsection{Promoting FWW activity will catalyse heritage activity more generally}

The value of promoting FWW activities then flows into a fourth assumption, that funding for FWW activities will catalyse heritage activity more generally, through increasing capacity of organisations to act and also by an increased understanding of the importance of heritage. One risk here, given some consideration by stakeholders, was whether there might equally be some displacement effects of FWW funding:

It would be interesting to know ... whether they chose to do a first world war project and put something else on the back burner, and whether there are organisations not coming forward in our other programmes because of the Centenary ... they may have felt that the First World War money may not go on. (Internal Stakeholder)

\subsubsection{A theory of change}

The overarching logic chain for the 'theory of change' behind the grant-funding for projects, incorporating the assumptions above, is summarised in Figure 2.1, below. As noted above this model is a construction created by the evaluation team drawing 
from interviews with HLF stakeholders and HLF documentary data, rather than something developed and used by HLF in the design of the FWW Centenary activity. The model shows how inputs (finances and advice and guidance provided by HLF and other organisations) lead through to activities (projects), and then - in turn outputs and outcomes. The basic logic behind the activities is relatively straightforward: funding the right projects leads to achievement of HLF outcomes.

Figure 2.1: a logic chain map for FWW Centenary activity In diagram below, 'support' from HLF needs to change to 'funding from HLF'

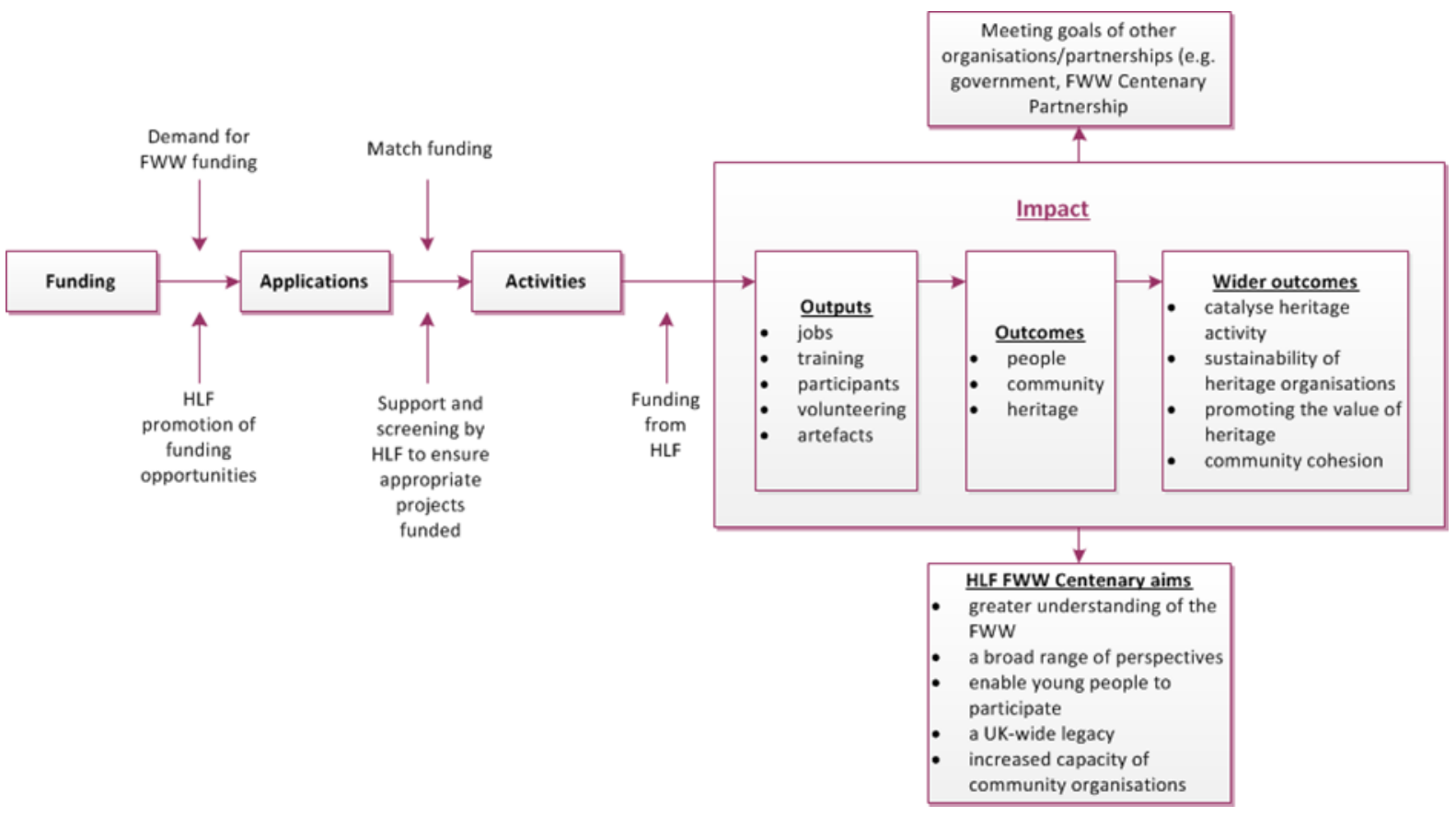

\subsection{Conclusion}

This chapter set out the background to the HLF's FWW Centenary activity, including mapping out the theory of change behind the activity. It showed how the activity might be understood within a theory of change model, and the assumptions that underpinned this. The next section moves on to exploring the 'activities' element of the logic chain: what took place and who was involved? 


\section{What has happened and who is involved in Centenary activities?}

\subsection{Introduction}

This section looks at the nature of the FWW Centenary activities funded through HLF. It considers the themes covered by activities; the types of activities; who participated in activities; and how projects sought to promote their activities. These findings are based on survey responses from 60 grant recipients alongside qualitative case study material. Findings at this early stage in the evaluation suggest a broad range of activities and themes were covered, engaging large numbers of people. Demographic analysis suggests that engaging with some black, Asian and minority ethnic groups might be proving a challenge.

\subsection{Where were FWW Centenary projects?}

Data on HLF FWW Centenary project awards shows that activities were taking place across all regions of the UK, as shown in Table 3.1, below. Distribution can be measured in a number of ways, including:

- $\quad$ overall number of projects

- overall grant awarded

- percentage of grant awarded through the Then and Now stream. Because projects funded through other streams are likely to be larger, but fewer in number, this measure removes the effect that single large grants might have on the data

This shows a broadly even spread of numbers of projects, taking into account population distribution, with some small outliers:

- The North East had a higher number of projects proportionate to its population size than other regions and countries of the UK.

- London and Northern Ireland received proportionately significantly more grant funding than other regions/countries: this can be accounted for by the investment in the IWM and HMS Caroline respectively.

- Northern Ireland received a slightly higher share of the Then and Now funding stream proportionate to its population compared to other regions and countries of the UK. 
Table 3.1: Regional spread of FWW Centenary projects

\begin{tabular}{|l|r|r|r|r|}
\hline Region & $\begin{array}{r}\text { Percentage } \\
\text { of projects } \\
\text { by number }\end{array}$ & $\begin{array}{r}\text { Percentage of } \\
\text { grant awarded } \\
\text { by value }\end{array}$ & $\begin{array}{r}\text { Percentage of } \\
\text { Then and Now } \\
\text { grant awarded }\end{array}$ & $\begin{array}{r}\text { Percentage } \\
\text { of Population }\end{array}$ \\
\hline East Midlands & $9 \%$ & $3 \%$ & $10 \%$ & $7 \%$ \\
\hline East of England & $8 \%$ & $2 \%$ & $8 \%$ & $9 \%$ \\
\hline London & $10 \%$ & $27 \%$ & $8 \%$ & $13 \%$ \\
\hline North East & $8 \%$ & $3 \%$ & $7 \%$ & $4 \%$ \\
\hline North West & $10 \%$ & $4 \%$ & $12 \%$ & $11 \%$ \\
\hline Northern Ireland & $4 \%$ & $22 \%$ & $4 \%$ & $2 \%$ \\
\hline Scotland & $8 \%$ & $2 \%$ & $8 \%$ & $8 \%$ \\
\hline South East & $11 \%$ & $10 \%$ & $10 \%$ & $14 \%$ \\
\hline South West & $11 \%$ & $7 \%$ & $10 \%$ & $8 \%$ \\
\hline Wales & $6 \%$ & $8 \%$ & $7 \%$ & $5 \%$ \\
\hline West Midlands & $10 \%$ & $4 \%$ & $12 \%$ & $9 \%$ \\
\hline $\begin{array}{l}\text { Yorkshire and The } \\
\text { Humber }\end{array}$ & $\mathbf{7} \%$ & $\mathbf{7} \%$ & $5 \%$ & $8 \%$ \\
\hline Total & $\mathbf{1 0 0} \%$ & $\mathbf{1 0 0} \%$ & $\mathbf{1 0 0} \%$ & $\mathbf{1 0 0 \%}$ \\
\hline
\end{tabular}

\subsection{What size of grants were awarded?}

HLF grant award data (March 2015) is presented according to grant size in Table 3.2. It shows that a large majority of grants were small: 75 per cent were for $£ 10,000$ or less and 12 per cent were for between $£ 10,000$ and $£ 50,000$. It also shows that although only a few very large grants of $£ 1$ million or more were awarded these accounted for more than half ( 57 per cent) of the value of grants awarded. The wide range of grant size awarded - from $£ 3,000$ to $£ 12.4$ million - highlights the breadth and complexity of FWW Centenary projects.

Table 3.2: Size of grants awarded

\begin{tabular}{|l|c|c|c|c|}
\hline & $\mathbf{n}$ & $\begin{array}{c}\text { Percentage } \\
\text { by number }\end{array}$ & Total value & $\begin{array}{c}\text { Percentage } \\
\text { by value }\end{array}$ \\
\hline$£ 10,000$ or less & 866 & $75 \%$ & $£ 6,913,300$ & $10 \%$ \\
\hline $\begin{array}{l}\text { More than } £ 10,000 \text { but less } \\
\text { than } £ 50,000\end{array}$ & 143 & $12 \%$ & $£ 4,505,900$ & $7 \%$ \\
\hline $\begin{array}{l}\text { More than } £ 50,000 \text { but less } \\
\text { than } £ 100,000\end{array}$ & 115 & $10 \%$ & $£ 8,423,400$ & $12 \%$ \\
\hline $\begin{array}{l}\text { More than } £ 100,000 \text { but } \\
\text { less than } £ 1 \text { million }\end{array}$ & 23 & $2 \%$ & $£ 9,489,100$ & $14 \%$ \\
\hline$£ 1$ million or more & 8 & $1 \%$ & $£ 38,872,400$ & $57 \%$ \\
\hline Total & 1155 & & $£ 68,204,100$ & \\
\hline
\end{tabular}

\subsection{What kinds of organisations were funded?}

HLF project data categorises grant recipients by organisation type. This is shown in table 3.3, below. It shows that over half of organisations were identified as 'community/voluntary' and one-fifth were local authorities. This follows from the focus of Then and Now in particular on community heritage projects. 
Table 3.3: Types of organisation funded

\begin{tabular}{|l|l|l|}
\hline Organisation type & & \\
\hline Church / Other Faith & 47 & $4 \%$ \\
\hline Commercial Organisation & 5 & $<1 \%$ \\
\hline Community / Voluntary & 716 & $59 \%$ \\
\hline Local Authority & 255 & $21 \%$ \\
\hline Other Public Sector & 199 & $16 \%$ \\
\hline Private Individual & 1 & $<1 \%$ \\
\hline & 1223 & $100 \%$ \\
\hline
\end{tabular}

Source: HLF project data May 2015

\subsection{What did funded projects do?}

The Grant Recipient Survey asked a range of questions about the types of activities funded projects undertook to mark the FWW Centenary. Categories included the First World War themes covered, conservation and other heritage based tasks, and the types of specific activities they provided. Data from this survey is also supplemented with HLF data for all FWW Centenary projects.

\subsubsection{Heritage type covered}

HLF records the one main category of heritage on which each project focuses. This is shown in Table 3.4, below. Almost half of all projects (46 per cent) are identified as community heritage, reflecting the focus of the Then and Now programme.

Table 3.4: Type of heritage covered by projects

\begin{tabular}{|l|l|l|}
\hline Heritage type & Number & Percentage \\
\hline Community heritage & 582 & $46 \%$ \\
\hline Historic buildings and monuments & 55 & $4 \%$ \\
\hline Industrial, maritime and transport & 13 & $1 \%$ \\
\hline Intangible heritage & 429 & $34 \%$ \\
\hline Land and biodiversity & 5 & $<1 \%$ \\
\hline $\begin{array}{l}\text { Museums, Libraries, Archives and } \\
\text { Collections }\end{array}$ & 169 & $13 \%$ \\
\hline Total & 1253 & $100 \%$ \\
\hline
\end{tabular}

Source: HLF project data May 2015

\subsubsection{First World War themes covered}

Table 3.5 provides an overview of the different types of First World War themes covered by the funded projects ${ }^{3}$. It demonstrates the broad focus of many projects but also highlights that understanding the impact of the FWW on the local community is of central importance to a majority of projects: more than nine out of ten projects focus on local people's experience of the war and four in five projects explored the impact of the war on the local area and the lives of people commemorated on war memorials. However, the survey responses also demonstrate that many projects

\footnotetext{
${ }^{3}$ This list of themes was created by the evaluation team in conjunction with HLF based on a review of existing project data and discussions relating to the various broad themes that might be covered in relation to the FWW
} 
have also sought to capture the global nature of the FWW. For example, nearly twothirds covered the war in Europe, more than a third explored the experiences of the wider British Empire and Commonwealth, and a quarter looked at the involvement of people from beyond the Empire or Commonwealth.

The survey responses also show that many projects have focused on specific aspects of the FWW, covering a broad range of themes. For example, more than half looked at the experiences of women and a similar number focused on understanding the war on the ground. Other popular themes included conscription, children, and propaganda. However, the survey data does not tell us the level of focus on each of these areas: it might be that some themes were covered only superficially. On average, respondents indicated that they covered 13 of the 29 options provided in the survey, which supports this theory, as does analysis of project applications. This reveals, for example, that only 13 per cent of projects mentioned women in their project description as opposed to the 58 per cent of Grant Recipient survey respondents that said the experiences of women were covered in their projects. Similarly, only seven per cent of projects mentioned the wartime economy or related issues in their project description, compared to the 30 per cent of Grant Recipient survey respondents 
Table 3.5: First World War themes covered by funded projects

\begin{tabular}{|c|c|c|}
\hline & $n$ & $\%$ \\
\hline Local people & 55 & $92 \%$ \\
\hline The impact of the war on the local area & 48 & $80 \%$ \\
\hline The lives of people commemorated on war memorials & 48 & $80 \%$ \\
\hline War memorials & 44 & $73 \%$ \\
\hline People from the UK who served abroad or at home & 43 & $72 \%$ \\
\hline War in Europe & 39 & $65 \%$ \\
\hline Women & 35 & $58 \%$ \\
\hline War on the ground & 35 & $58 \%$ \\
\hline Conscription and recruitment & 33 & $55 \%$ \\
\hline Children & 27 & $45 \%$ \\
\hline Propaganda & 27 & $45 \%$ \\
\hline War at sea & 25 & $42 \%$ \\
\hline Food and agriculture & 25 & $42 \%$ \\
\hline Culture in wartime & 25 & $42 \%$ \\
\hline Industry & 23 & $38 \%$ \\
\hline People from/in British Empire/Commonwealth & 22 & $37 \%$ \\
\hline Dissent/objection to the war & 20 & $33 \%$ \\
\hline Disabled soldiers & 19 & $32 \%$ \\
\hline War in the air & 19 & $32 \%$ \\
\hline Economy & 18 & $30 \%$ \\
\hline Medicine and healthcare & 18 & $30 \%$ \\
\hline Impact of the war after 1918 & 18 & $30 \%$ \\
\hline War outside Europe & 16 & $27 \%$ \\
\hline Sport in wartime & 16 & $27 \%$ \\
\hline People from/in countries outside the British Empire & 15 & $25 \%$ \\
\hline How the war has been commemorated since 1918 & 15 & $25 \%$ \\
\hline Animals in war & 14 & $23 \%$ \\
\hline Faith communities & 12 & $20 \%$ \\
\hline Beliefs & 11 & $18 \%$ \\
\hline
\end{tabular}

Source: Grant Recipient Survey (2014-15)

Base: All valid responses $(n=60)$ 


\subsubsection{Conservation and other heritage tasks}

Table 3.6 provides an overview of the types of conservation and other heritage based tasks undertaken by funded projects. Respondents were asked to indicate which types of conservation and other heritage tasks they were undertaking from a list of predetermined list of activities. ${ }^{4}$ This highlights the central role of collecting new historical source material such as documents, photographs, oral histories and artefacts in a large majority of funded projects (more than nine in ten). Similarly, activities that involve cataloguing (including digitisation) archive material and conserving archives and artefacts have been an important focus of funded activity so far.

Table 3.6: Conservation and other heritage tasks undertaken by funded projects

\begin{tabular}{|l|r|r|}
\hline & $\boldsymbol{n}$ & $\%$ \\
\hline $\begin{array}{l}\text { Collect new material, such as documents, } \\
\text { photographs, oral histories or artefacts }\end{array}$ & 49 & $92 \%$ \\
\hline Catalogue or digitise archive material & 30 & $57 \%$ \\
\hline Conserve archive material & 25 & $47 \%$ \\
\hline Conserve one or more artefacts & 16 & $30 \%$ \\
\hline Create a new war memorial & 10 & $19 \%$ \\
\hline Conserve a war memorial & 8 & $15 \%$ \\
\hline Conserve a historic building, monument or site & 2 & $4 \%$ \\
\hline
\end{tabular}

Source: Grant Recipient Survey (2014-15)

Base: All valid responses $(n=60)$

Grant recipient survey respondents were also asked what outputs their projects had created, as shown in Table 3.7, below. Over two-thirds of projects produced a website as part of their projects, and over half had produced a display or temporary exhibition. Fewer projects had produced permanent exhibitions, with less than one in ten creating a permanent exhibition in a community venue or a permanent exhibition in a museum, heritage centre, gallery or library.

\footnotetext{
${ }^{4}$ Unless otherwise indicated, all survey responses are based on closed option questions, with the options developed by HLF and/or the evaluation team
} 
Table 3.7: Outputs created by funded projects

\begin{tabular}{|l|l|l|}
\hline & $\mathbf{n}$ & $\mathbf{\%}$ \\
\hline Website & 40 & $69 \%$ \\
\hline Display board & 36 & $62 \%$ \\
\hline $\begin{array}{l}\text { A temporary exhibition in a museum, heritage centre, gallery or } \\
\text { library }\end{array}$ & 30 & $52 \%$ \\
\hline A temporary exhibition in a community venue & 30 & $52 \%$ \\
\hline Leaflet or book & 30 & $52 \%$ \\
\hline Film & 29 & $50 \%$ \\
\hline Performance & 23 & $40 \%$ \\
\hline Pack for schools & 17 & $29 \%$ \\
\hline Trail & 10 & $17 \%$ \\
\hline $\begin{array}{l}\text { A permanent exhibition in a museum, heritage centre, gallery or } \\
\text { library }\end{array}$ & 5 & $9 \%$ \\
\hline A permanent exhibition in a community venue & 5 & $9 \%$ \\
\hline Smartphone app & 3 & $5 \%$ \\
\hline Other & 13 & $22 \%$ \\
\hline
\end{tabular}

Source: Grant Recipient Survey (2014-15)

Base: All valid responses $(n=58)$

\subsubsection{The range of activities provided}

Table 3.8 provides an overview of the range of activities provided by funded projects. ${ }^{5}$ It includes:

- $\quad$ the number and percentage of projects undertaking each activity;

- the total number of each activity provided; and

- the total number of participants involved in each type of activity.

Similar to responses regarding First World War themes, the responses highlight the local focus of a majority of funded activities. More than nine in ten projects said they held community events and participants in community events $(40,079)$ accounted for more than half of all participants in specific types of activity.

Other prominent activities provided included talks by experts (more than half of projects), visits and outreach with schools and colleges (around half of projects) and outreach sessions in community venues (around two-fifths of projects). 
Table 3.8: Overview of activities undertaken by funded projects

\begin{tabular}{lrrrr}
\hline & $\boldsymbol{n}$ & $\%$ & $\begin{array}{r}\text { No. of } \\
\text { activities } \\
\text { provided }\end{array}$ & $\begin{array}{r}\text { No. of } \\
\text { participant } \\
\text { S }\end{array}$ \\
\hline Community event & 55 & $92 \%$ & 203 & 40,079 \\
$\begin{array}{l}\text { Talk from First World War experts } \\
\text { Workshop with heritage organisations such }\end{array}$ & 35 & $58 \%$ & 235 & 9,295 \\
$\begin{array}{l}\text { as museums, libraries, archives or local } \\
\text { history societies }\end{array}$ & 24 & $40 \%$ & 92 & 5,883 \\
$\begin{array}{l}\text { Outreach session in schools or colleges } \\
\text { Visit from schools or colleges }\end{array}$ & 29 & $48 \%$ & 182 & 5,803 \\
$\begin{array}{l}\text { Outreach session in community venues } \\
\text { Guided tour, walk or visit }\end{array}$ & 29 & $48 \%$ & 169 & 5,104 \\
$\begin{array}{l}\text { Workshop with arts organisations or arts } \\
\text { professionals }\end{array}$ & 17 & $42 \%$ & 529 & 3,196 \\
Accredited training course & 11 & $18 \%$ & 40 & 1,458 \\
Non-accredited training course & 3 & $5 \%$ & 16 & 580 \\
\hline
\end{tabular}

Source: Grant Recipient Survey (2014-15)

Base: All valid responses $(n=60)$

\subsubsection{Who participated in funded projects?}

Overall, the 64 funded projects that responded to the Grant Recipient Survey reported having $\mathbf{7 6 8 , 5 7 8}$ participants: ${ }^{67}$ This figure includes a number of projects that were already complete (43) and a number of longer term projects that had been up and running for at least 12 months (21).

It should be noted that projects lasting more than one year contributed many more participants (93 per cent; 34,343 per project) than completed projects ( 7 per cent; 1,346 per project). This is because longer term projects tend to be larger, visitor based attractions whereas completed projects tend to be short in duration and have more of a community focus. A banded breakdown of the number of participants is provided in Table 3.9 to illustrate this point in more detail. This shows how projects ranged widely in their 'reach', with a relatively even split across different bands of participant numbers between 'less than 100' and up to 5,000 participants. This should be expected in line with the variation in project funding, scope, focus and outputs.

\footnotetext{
${ }^{6}$ Note that this figure and subsequent analyses excludes the Imperial War Museum First World War Galleries, which had over one million visitors in 2014/15.

${ }^{7}$ It should be noted than many projects, particularly smaller ones with a community focus, do not currently collect systematic monitoring data on the characteristics of their participants. As such, much of the data collected is based on projects' best estimates of the numbers and percentages involved. As part of the Evaluation of HLF's First World War Centenary Funded Activity the evaluation team has worked with HLF and its grantees to develop Self-evaluation Guidance with the aim of improving the capacity of projects to capture this type of data in the future.
} 
Table 3.9: Banded breakdown of number of participants in funded projects

\begin{tabular}{|l|c|c|c|c|c|c|}
\hline \multirow{2}{*}{ Number of participants: } & \multicolumn{2}{|c|}{ Overall } & \multicolumn{2}{c|}{ Completed projects } & \multicolumn{2}{c|}{ Longer term projects } \\
\cline { 2 - 7 } & $n$ & $\%$ & $n$ & $\%$ & $n$ & $\%$ \\
\hline Less than 100 & 12 & $20 \%$ & 9 & $22 \%$ & 3 & $17 \%$ \\
\hline Between 100 and 500 & 16 & $27 \%$ & 11 & $27 \%$ & 5 & $28 \%$ \\
\hline Between 500 and 1,000 & 12 & $20 \%$ & 9 & $22 \%$ & 3 & $17 \%$ \\
\hline Between 1,000 and 5,000 & 12 & $20 \%$ & 9 & $22 \%$ & 3 & $17 \%$ \\
\hline 5,000 or more & 7 & $12 \%$ & 3 & $7 \%$ & 4 & $22 \%$ \\
\hline
\end{tabular}

Source: Grant Recipient Survey (2014-15)

Base: All valid responses $(n=59)$

Project participants include any individual that may have participated in one or more of the activities held as well as members of the organisations and groups (staff and/or volunteers) in receipt of HLF funding. Survey respondents also provided data on the demographic make-up of participants as well as specific data about volunteers and training recipients, an overview of which is provided in the following sections.

\subsubsection{Demographic characteristics of participants in funded projects}

Table 3.10 provides an overview of the age, gender and ethnicity of participants in HLF-funded FWW Centenary projects. This demonstrates that participation was evenly distributed by gender but there were some significant variations according to age and ethnicity. More than three-quarters of participants were adults aged over 26 and there were a significant number - more than a third - aged 65 or over. By contrast 18 per cent of participants were of school or college age. In terms of ethnicity, almost nine in 10 were White British with far fewer from specific black, Asian and minority ethnic groups. ${ }^{8}$

\footnotetext{
${ }^{8}$ It should be noted that respondents were not always consistent in the way that they reported on demographics, especially in terms of ethnicity: e.g. some respondents gave a rounded estimate of proportions, while others appeared to give more precise figures. Any discrepancies caused by these differences will be ironed out as the dataset grows over the course of the evaluation.
} 
Table 3.10: Demographic characteristics of participants in funded projects

\begin{tabular}{|c|c|c|c|}
\hline & $n$ & $\%$ & UK Population (\%) \\
\hline \multicolumn{4}{|l|}{ Age: } \\
\hline Five or under & 36,800 & $5 \%$ & $8 \%$ \\
\hline Six to 10 & 86,290 & $11 \%$ & $6 \%$ \\
\hline $11-16$ & 45,391 & $6 \%$ & $7 \%$ \\
\hline 17 to 18 & 8,386 & $1 \%$ & $2 \%$ \\
\hline $19-25$ & 13,673 & $2 \%$ & $9 \%$ \\
\hline $26-59$ & 311,698 & $41 \%$ & $46 \%$ \\
\hline 60 and over & 266,340 & $35 \%$ & $22 \%$ \\
\hline \multicolumn{4}{|l|}{ Gender: } \\
\hline Male & 369,642 & $49 \%$ & $49 \%$ \\
\hline Female & 383,013 & $51 \%$ & $51 \%$ \\
\hline & $n$ & $\%$ & UK Population (\%) \\
\hline \multicolumn{4}{|l|}{ Ethnicity: } \\
\hline White & 660,879 & $88 \%$ & $87 \%$ \\
\hline Mixed ethnic group ${ }^{9}$ & 67,398 & $9 \%$ & $2 \%$ \\
\hline $\begin{array}{l}\text { Asian } \\
\text { (Bangladeshi, Indian, Pakistani, } \\
\text { other) }\end{array}$ & 9,755 & $1 \%$ & $6 \%$ \\
\hline $\begin{array}{l}\text { Black } \\
\text { (Caribbean, African, other) }\end{array}$ & 3,816 & $1 \%$ & $3 \%$ \\
\hline Other & 3,466 & $0 \%$ & $1 \%$ \\
\hline Chinese & 2,366 & $0 \%$ & $1 \%$ \\
\hline Irish traveller & 32 & $0 \%$ & $0 \%$ \\
\hline
\end{tabular}

Source: Grant Recipient Survey (2014-15); UK Office for National Statistics (2013)

Base: All valid responses $(n=58)$

\subsubsection{People who volunteered in funded projects}

Overall, 95 per cent of respondents to the Grant Recipient Survey reported having used volunteers in their FWW Centenary project. This amounted to almost 2,600 people providing more than 16,000 hours of their time willingly and free-of-charge. Table 3.11 provides an overview of the types of roles were involved in while Table 3.12 provides an overview of these volunteers' demographic characteristics.

\footnotetext{
${ }^{9}$ This figure is higher than might be expected. We cannot be certain why this is, but believe it might be that some respondents have used this box as a catch-all for any people of non-White British ethnicity. The survey will be amended from Year 2 onwards with a note that makes clear the meaning of this category.
} 
Table 3.11: Overview of volunteer roles within funded projects

\begin{tabular}{|l|r|r|}
\hline & $\boldsymbol{n}$ & $\%$ \\
\hline $\begin{array}{l}\text { Coordinating or leading activities } \\
\text { (e.g. as a member of a committee/management group) }\end{array}$ & 43 & $75 \%$ \\
\hline Researching and working with existing collections and archives & 43 & $75 \%$ \\
\hline Helping with marketing and publicity & 43 & $75 \%$ \\
\hline Gathering, recording, analysing and cataloguing new material & 41 & $72 \%$ \\
\hline Providing administrative or IT support for the project & 38 & $67 \%$ \\
\hline $\begin{array}{l}\text { Devising and delivering activities for the wider public } \\
\text { (e.g. talks and small exhibitions) }\end{array}$ & 36 & $63 \%$ \\
\hline $\begin{array}{l}\text { Providing other support to the project } \\
\text { (e.g. catering, cleaning) }\end{array}$ & 32 & $56 \%$ \\
\hline Devising and delivering activities for schools & 31 & $54 \%$ \\
\hline $\begin{array}{l}\text { Devising and delivering activities for children and young people } \\
\text { outside of school (e.g. in youth groups) }\end{array}$ & 17 & $30 \%$ \\
\hline $\begin{array}{l}\text { Conservation activities } \\
\text { (e.g. on natural landscapes, or industrial/military heritage) }\end{array}$ & 6 & $11 \%$ \\
\hline
\end{tabular}

Source: Grant Recipient Survey (2014-15)

Base: All valid responses $(n=57)$

The most frequently identified roles were directly related to the provision of funded activities: three-quarters of respondents said volunteers coordinated and led activities or were involved in research and archival work while almost two-thirds devised and delivered roles to the wider public; more than half did this for schools and almost a third did so for young people outside of school. The survey responses also highlight the important roles volunteers played in supporting the wider operation of funded projects: three-quarters were involved in marketing and publicity, more than two-thirds provided administrative or IT support and more than half provided other types of support such as cleaning or catering. 
Table 3.12: Demographic characteristics of volunteers in funded projects

\begin{tabular}{|c|c|c|}
\hline & $n$ & $\%$ \\
\hline \multicolumn{3}{|l|}{ Age: } \\
\hline $1-16$ & 59 & $2 \%$ \\
\hline $17-18$ & 108 & $4 \%$ \\
\hline $19-25$ & 210 & $8 \%$ \\
\hline $26-59$ & 1,158 & $44 \%$ \\
\hline 60 and over & 1,101 & $42 \%$ \\
\hline \multicolumn{3}{|l|}{ Gender: } \\
\hline Male & 1,118 & $43 \%$ \\
\hline Female & 1,513 & $57 \%$ \\
\hline \multicolumn{3}{|l|}{ Ethnicity: } \\
\hline White & 2,469 & $95 \%$ \\
\hline Mixed ethnic group & 41 & $2 \%$ \\
\hline Other & 22 & $1 \%$ \\
\hline $\begin{array}{l}\text { Asian } \\
\text { (Bangladeshi, Indian, Pakistani, other) }\end{array}$ & 21 & $1 \%$ \\
\hline Chinese & 17 & $1 \%$ \\
\hline $\begin{array}{l}\text { Black } \\
\text { (Caribbean, African, other) }\end{array}$ & 19 & $1 \%$ \\
\hline Irish traveller & - & $0 \%$ \\
\hline
\end{tabular}

Source: Grant Recipient Survey (2014-15)

Base: All valid responses $(n=57)$

Table 3.12 demonstrates that similar to overall participation, volunteers were relatively evenly distributed by gender but there were some significant variations according to age and ethnicity. In terms of age, almost nine in ten volunteers were adults aged over 26 and more than two-fifths were aged 65 or over. In terms of ethnicity, a large majority of volunteers were White with very few from specific black, Asian and minority ethnic groups.

\subsubsection{People who received training through funded projects}

Overall, 41 per cent of projects provided staff, volunteers or participants with training as part of their involvement in a FWW Centenary project. This amounted to 447 people trained. Table 3.13 provides an overview of the types of training received while Table 3.14 provides an overview of the demographic characteristic of training recipients. 
Table 3.13: Types of training received by participants in funded projects

\begin{tabular}{|l|r|r|}
\hline & $\boldsymbol{n}$ & $\boldsymbol{\%}$ \\
\hline Media skills, including websites, films and recordings & 15 & $68 \%$ \\
\hline $\begin{array}{l}\text { Delivering participation, including participation and volunteer } \\
\text { management }\end{array}$ & 13 & $59 \%$ \\
\hline Delivering learning or interpretation & 12 & $55 \%$ \\
\hline Conservation of collections, including oral history & 8 & $36 \%$ \\
\hline Conservation of other types of First World War heritage & 4 & $18 \%$ \\
\hline $\begin{array}{l}\text { Managing heritage sites, including customer care and } \\
\text { marketing }\end{array}$ & 2 & $9 \%$ \\
\hline
\end{tabular}

Source: Grant Recipient Survey (2014-15)

Base: All valid responses $(n=23)$

Table 3.13 demonstrates the most commonly identified types of training were media skills, participation and volunteering, and learning/interpreting, all of which were provided by more than half of projects who provided training. Specific heritage-based training was less common, although more than a third of those providing training did provide courses associated with conservation/oral history, and around a fifth focused on training associated with conserving FWW heritage specifically.

Table 3.14: Demographic characteristics of training recipients

\begin{tabular}{|c|c|c|}
\hline & $n$ & $\%$ \\
\hline \multicolumn{3}{|l|}{ Age: } \\
\hline $1-16$ & 68 & $16 \%$ \\
\hline $17-18$ & 12 & $3 \%$ \\
\hline $19-25$ & 56 & $13 \%$ \\
\hline $26-59$ & 156 & $36 \%$ \\
\hline 60 and over & 137 & $32 \%$ \\
\hline \multicolumn{3}{|l|}{ Gender: } \\
\hline Male & 199 & $46 \%$ \\
\hline Female & 233 & $54 \%$ \\
\hline \multicolumn{3}{|l|}{ Ethnicity: } \\
\hline White & 348 & $81 \%$ \\
\hline Mixed ethnic group & 24 & $6 \%$ \\
\hline $\begin{array}{l}\text { Asian } \\
\text { (Bangladeshi, Indian, Pakistani, other) }\end{array}$ & 20 & $5 \%$ \\
\hline Other & 5 & $1 \%$ \\
\hline Black (Caribbean, African, other) & 3 & 0 \\
\hline Chinese & 2 & $0 \%$ \\
\hline Irish traveller & - & - \\
\hline
\end{tabular}

Source: Grant Recipient Survey (2014-15) 
Table 3.14 demonstrates that, similar to wider participants and volunteers, training recipients were relatively evenly distributed by gender but there were some significant variations according to age and ethnicity. In terms of age, more than twothirds of training recipients were adults aged over 26 and almost a third were aged 65 or over. In terms of ethnicity, four-fifths of training recipients were White with onefifth from other black, Asian and minority ethnic groups. This is considerably higher than for wider participants and volunteers.

Overall, these findings suggest that there might be challenge for projects to engage with people from non-White British backgrounds. This was also a theme of the case studies. In part, some respondents thought that the issue related to the perceived relevance of FWW projects to those from non-White British backgrounds, and perceived links to British nationalism or anti-migrant sentiments. However, some projects were actively seeking to break down these barriers. The Our World War One project in Brierfield, for example, sought to engage the local Asian community through a wide range of activities focusing on the role of the Indian Army (incorporating Bangladesh and Pakistan) in the FWW. This proved successful in both engaging participants from different backgrounds, and in attracting a range of different attendees to events.

\subsection{How did projects promote their activities?}

In addition to questions about activities and participants, the Grant Recipient Survey also asked respondents how they promoted their project, focusing in particular on the use of digital media and the online platform Historypin. ${ }^{10}$ Overall, 90 per cent of respondents promoted their project using some form of digital media. Table 3.15 provides an overview of the different types of digital media used. This shows that grantees' own websites were most commonly used, followed by Facebook, the FWW Centenary Partnership website and Twitter. In addition, about a third of projects said they had set up a new website specifically for their HLF-funded project.

Table 3.15: Use of digital media by funded projects

\begin{tabular}{|l|r|r|}
\hline & $\boldsymbol{n}$ & $\boldsymbol{\%}$ \\
\hline Your organisation/group's own website & 39 & $74 \%$ \\
\hline Facebook & 30 & $57 \%$ \\
\hline First World War Centenary partnership (www.1914.org) & 26 & $49 \%$ \\
\hline Twitter & 21 & $40 \%$ \\
\hline A new website created for the project & 19 & $36 \%$ \\
\hline
\end{tabular}

Source: Grant Recipient Survey (2014-15)

Base: All valid responses $(n=53)$

In terms of Historypin, overall 83 per cent of respondents said they had used it in some way as part of their HLF-funded project. An overview of how they used it is provided in Table 3.16 which shows that four-fifths of respondents used it to create a page about their HLF-funded project, just under a quarter used it to share heritage

\footnotetext{
${ }^{10}$ The' First World Ward Centenary Hub' on Historypin is an online digital map which provides a place for projects to share heritage material and record their activities online. HLF funded projects have been encouraged to create a page on the Historypin Hub and use it to share information about their project. See:

www.historypin.com/en/explore/first-world-war-centenary include date it went live- Oct 2014
} 
materials or find out about other FWW projects in their area, and just over a fifth used it to share other outputs of their project such as photos or films.

Table 3.16: Use of Historypin by funded projects

\begin{tabular}{|l|r|r|}
\hline & $\boldsymbol{n}$ & $\%$ \\
\hline $\begin{array}{l}\text { Create a project page in order to promote and share } \\
\text { information about your HLF funded project }\end{array}$ & 22 & $42 \%$ \\
\hline Share heritage materials, such as photos or documents & 12 & $23 \%$ \\
\hline $\begin{array}{l}\text { Find out about other First World War projects or activities in } \\
\text { your area }\end{array}$ & 12 & $23 \%$ \\
\hline $\begin{array}{l}\text { Share outputs of your project such as photos of activities or } \\
\text { films }\end{array}$ & 11 & $21 \%$ \\
\hline $\begin{array}{l}\text { Find out about other First World War projects or activities } \\
\text { similar to yours }\end{array}$ & 8 & $15 \%$ \\
\hline
\end{tabular}

Source: Grant Recipient Survey (2014-15)

Base: All valid responses $(n=53)$

\subsection{Why did projects and participants get involved with FWW Centenary activities?}

The Grant Recipient and Participant surveys both included questions asking what motivated individuals or organisations to either deliver a project, or to get involved with a project. These are considered in turn, below.

\subsubsection{Motivations to deliver a project}

Respondents to the Grant Recipient Survey were given the opportunity to provide a free text response to the questions "what motivated you and/or your organisation to do your First World War Centenary project". Respondents gave a range of responses, but almost all of the projects referred to the importance of doing something to mark the Centenary in and of itself, as highlighted in the following response:

c.800 people in our borough gave their lives in the First World War and it was important that they were remembered, honoured, and that current residents saw them as people and not just a list of names on a memorial (Grant Recipient Survey respondent)

Another significant theme was the use of the Centenary as a theme for existing or planned activities. For instance one school used the Centenary as a theme for their annual 'off-curriculum' week, and a church in Wales who carried out projects relating to the local community each year used it as their theme for the year. Other prominent themes included:

- following-up from a previous community, heritage or FWW project: for instance one project reported that "Having organised a successful WW2 Nostalgia event in 2012, as part of the Queen's Jubilee Celebrations, we saw this as an opportunity to commemorate the lives of the local fallen heroes of WW1." (Grant Recipient Survey respondent)

- a desire to engage young people with FWW heritage: "we thought that this would be a great opportunity to engage young people in what some might think is a 'dry' subject." (Grant Recipient Survey respondent) 
- a desire to engage the local community in FWW heritage: "we wanted to involve our local community in learning about the impact WW1 had on the town" (Grant Recipient Survey respondent)

- $\quad$ wanting to conduct repairs to war memorials: "the War Memorial had a splitting base and was gradually being undermined by the weather. It was decided to repair the base and also realign the footpath in the garden to its former route" (Grant Recipient Survey respondent)

- $\quad$ personal interest in a subject related to the FWW Centenary: "we discovered that male impersonator Ella Shields originally popularised the song 'Oh, it's a Lovely War!' which later inspired the show 'Oh, What a Lovely War!'. We became fascinated by the popularity of male impersonators Vesta Tilley, Ella Shields and Hetty King and how their emancipation and unconventional appearance on stage reflected the greater freedoms women were gaining during the First World War. " (Grant Recipient Survey respondent)

\subsubsection{Motivations to get involved with a project}

Respondents to the Participant survey were also asked why they decided to take part in FWW Centenary activities, and were asked to choose from a list of options. The responses are summarised in Table 3.17, below. It shows that over half (20 out of 34 respondents) of participants took part to learn more about the FWW in the local area, and also out of a desire to personally commemorate the FWW Centenary (18 out of 34). The latter chimes with the motivations given by Grant Recipients about the importance of marking the Centenary in itself.

Table 3.17 Motivations for taking part in projects

\begin{tabular}{|c|c|c|}
\hline & Number & Per cent \\
\hline To learn more about heritage & 9 & $26 \%$ \\
\hline $\begin{array}{l}\text { To learn about the history and heritage of the First World War in } \\
\text { general }\end{array}$ & 13 & $38 \%$ \\
\hline $\begin{array}{l}\text { To learn about the history and heritage of the First World War in } \\
\text { the local area }\end{array}$ & 20 & $59 \%$ \\
\hline I had an existing interest in the First World War & 15 & $44 \%$ \\
\hline $\begin{array}{l}\text { I wanted to commemorate the Centenary of the First World War } \\
\text { personally }\end{array}$ & 18 & $53 \%$ \\
\hline $\begin{array}{l}\text { I believe the topic explored by this project is not well known and } \\
\text { should be better understood by more people }\end{array}$ & 14 & $41 \%$ \\
\hline To learn some new skills (e.g. computing, research, transcribing) & 2 & $6 \%$ \\
\hline $\begin{array}{l}\text { To continue utilising and updating my existing skills (e.g. } \\
\text { teaching /presenting, business and management skills, IT skills) }\end{array}$ & 5 & $15 \%$ \\
\hline A friend or family member recommended me to get involved & 4 & $12 \%$ \\
\hline I was invited by the event organisers & 17 & $50 \%$ \\
\hline To learn more about/get more involved in the local community & 6 & $18 \%$ \\
\hline To help others & 8 & $24 \%$ \\
\hline To help look after heritage & 10 & $29 \%$ \\
\hline To meet new people/get out of the house & 6 & $18 \%$ \\
\hline Work experience/help in getting a job & 1 & $3 \%$ \\
\hline It was part of my school/college/university work & 2 & $6 \%$ \\
\hline
\end{tabular}

Base: 34 respondents 


\subsection{Conclusions}

This chapter provided analysis of the types of activity taking place across FWW Centenary activity, the people involved in activities (and the nature of their involvement) and the means by which projects had promoted activities. It highlighted some key successes, most notably in relation to the numbers of people participating in projects, and the important role being played by large numbers of volunteers in delivering projects.

Some other aspects of activities were less clear and will become clearer over time as the evidence base builds in the coming years. For instance the data on the demographic spread of participants is inconclusive, and there is an indication that some population groups might be being underrepresented, such as 18-25 year olds and some black, Asian and minority ethnic groups.

The following chapter moves on to consider how these activities have translated in outcomes measureable across the 14 HLF outcome areas. 


\section{What outcomes were achieved?}

\subsection{Introduction}

This chapter explores the extent and ways in which FWW Centenary activities have achieved different types of outcome, and specifically those that meet the HLF outcomes framework. The analysis here draws on data from the Participant and Grant Recipient Surveys and qualitative research undertaken with the five case studies. At the end of Year 1 the number of responses to individual participant survey questions are quite low, and so we have only referred to the raw numbers in the data rather than translating these into percentages, which could give a false sense of robustness in the data. Because the survey data is currently quite limited, at this stage in the evaluation the more detailed data are drawn largely from case study data. This will change in subsequent years when the participant dataset grows.

Some outcome areas are better evidenced than others at this stage. In particular, there is stronger evidence of people outcomes than in other areas. This is partly due to the still developing dataset, but is also owing to the nature of projects, which have tended to exhibit strong people outcomes but fewer heritage outcomes. Community outcomes are both harder to evidence and to achieve; however, there is some evidence of different community outcomes being met and the evaluation will seek to further explore these in future years.

\subsection{Outcomes for heritage}

The four HLF outcomes for heritage are as follows:

- $\quad$ heritage will be better managed

- $\quad$ heritage will be in better condition

- $\quad$ heritage will be better interpreted and explained

- $\quad$ heritage will be identified/recorded

Respondents to the Grant Recipient Survey were asked to provide their views about the types of outcomes their project had achieved. Respondents were asked to identify any outcome that they felt they had achieved and up to three main or most important outcomes from their project. This included two responses that related directly to outcomes for heritage: locating, uncovering or recording aspects of First World War heritage and improving the physical state of First World War heritage. The responses are summarised in Figure 4.1. 
Figure 4.1: Outcomes for heritage identified by grant recipients

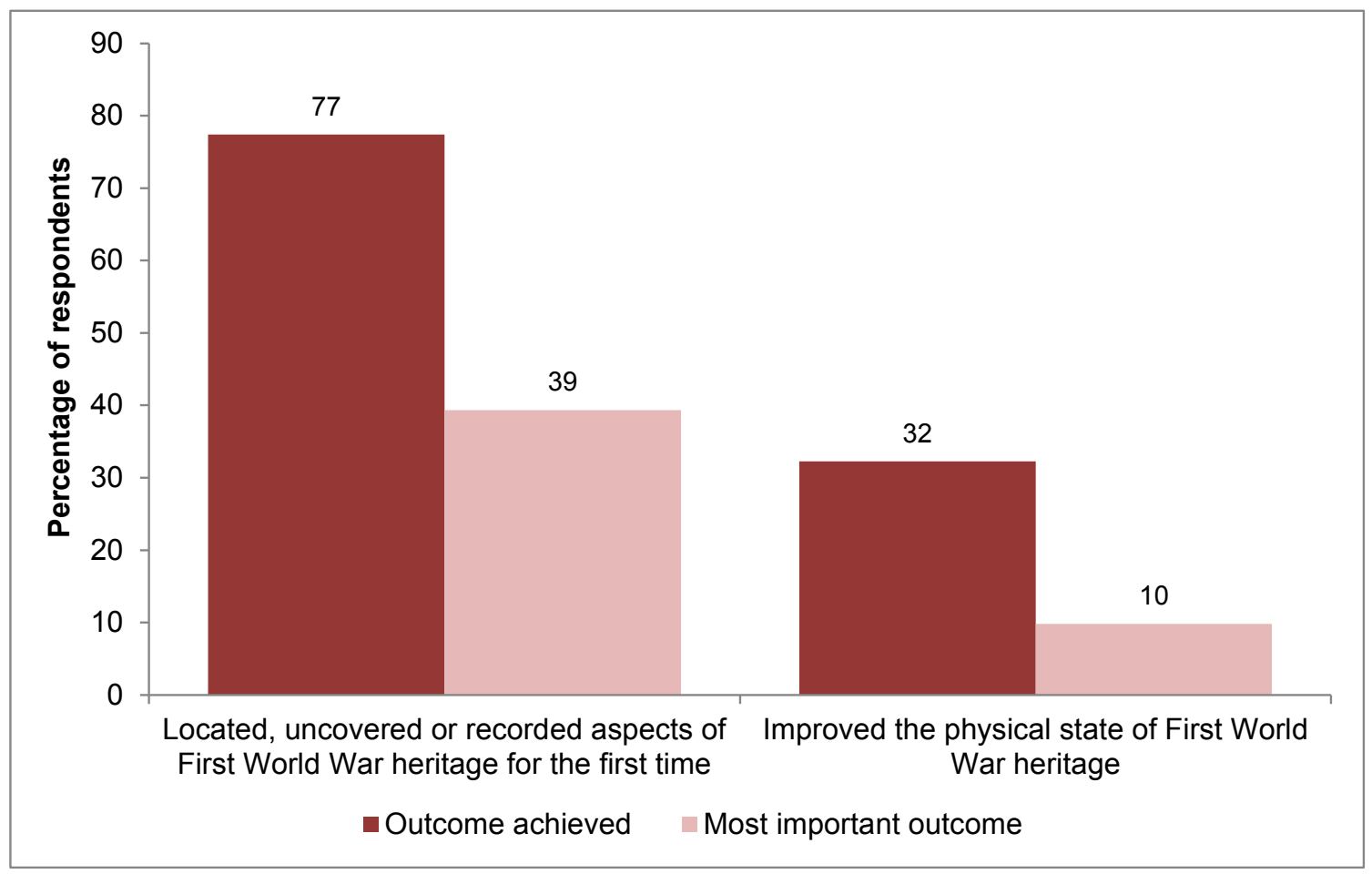

Source: Grant Recipient Survey (2014-15)

Base: All valid responses $(n=61)$

The data gives a useful overview as to what outcomes projects were working towards. Each of the heritage outcomes are now taken in turn to provide a more detailed understanding of how outcomes were being met.

\subsubsection{Heritage will be better managed}

This outcome area was not well evidenced. Three-quarters of projects received grants of under $£ 10,000$ and as such are perhaps unlikely to have implemented new structures to better manage heritage. However, the evaluation will endeavour to capture more on this outcome area in Year 2, potentially through inclusion of an additional question in the Grant Recipient Survey.

\subsubsection{Heritage will be in better condition}

Thirty-two per cent of Grant Recipient Survey respondents reported that their project had improved the physical state of FWW heritage, with 10 per cent regarding it as their most important outcome. Survey and case study data showed the range of ways in which this was being achieved, including the erection of new buildings to house FWW collections, repairing war memorials and improving / restoring archive materials. For instance, almost one in three (30\%) Grant Recipient survey respondents indicated that they had carried out work to conserve artefacts, and one in seven (15\%) indicated that they had worked to conserve a war memorial (See Section 3.3 above)

\subsubsection{Heritage will be better interpreted and explained}

The survey and qualitative data uncovered a wide range of ways in which heritage was being interpreted and explained in order to make it more accessible to different groups or people: in particular, young people. 
Table 3.7 in Chapter 3 showed the range of means through which projects sought to share their stories, including outreach sessions in schools and community venues, workshops and community events. And, as discussed in Section 3.4, the use of digital and social media was an important method of creating new means of interpreting and explaining heritage, used by 90 per cent of projects to share their stories. Table 3.8 in Chapter 3 showed the different outputs of projects, which also highlights a range of different means of interpreting and explaining heritage. Again, the use of websites figures highly (59 per cent of respondents), but the use of films (50 per cent) and performances (40 per cent) were also important media alongside more traditional means of communication such as exhibitions and displays.

This outcome was also evidenced by a number of comments made by survey respondents in relation to the "biggest success" of their project:

The booklets were the greatest success, we've had fantastic feedback and thanks from the schools, basically nothing but praise (Survey respondent)

It was a chance to work with external companies and challenge ourselves to offer a different take on the First World War than the normal 'exhibition' route [through the production of 25 short films]. (Survey respondent)

We researched the records of 260 men and a few women and produced the result in a published book. We also ran a successful exhibition in our Village Hall which ran over the weekend 13/14 September 2014 and a further exhibition in a pop-up shop in [nearby town] for a week. The exhibitions were seen by over 700 people including our local Mayor and Member of Parliament. (Survey respondent)

We re-enacted life in the Tintown Entertainment Hall, told the story of men building the Naval Base, hardships encountered and entertainment, starting with magic lanterns slide shows, silent movies with piano accompaniment, WWI songs sing along. We put on 30 shows during the week and this locally proved so successful we have shown it several times to local groups. Indeed we still have requests coming in to take the show "on the Road" again during 2015 (Survey respondent)

This shows how a range of more traditional 'analogue' and face-to-face means of sharing information remained important alongside the use of digital media.

In summary the early evidence is that FWW Centenary funding is being used to better interpret and explain heritage through a wide range of methods, with the possibility for projects of all sizes to engage in different activities to meet this outcome.

\subsubsection{Heritage will be identified/recorded}

As figure 4.1 above shows, the outcome heritage will be identified was viewed as an important outcome for most projects, with 77 per cent of projects stating that they had achieved this outcome and 39 per cent marking it out as their most important outcome. The data on overall projects funded gives a sense of the different ways in which projects aimed to achieve this outcome, with an emphasis on the preservation of personal life histories. This can be fleshed out with reference to the case studies. In Ballymena, for example, the On The Brink project activities, such as the workshops and research, are leading to the collection of previously untold stories. These are social and personal histories that have proved an important part of bringing the project alive. The project lead highlighted the danger of these stories being forgotten: 
We're flagging-up case studies, and uncovering histories, like you had a lot of them are not on the public domain yet. And they're forgotten, they're forgotten for various reasons (Project Lead, On The Brink)

\subsection{Outcomes for people}

Outcomes for people were the most well-evidenced outcome areas in the first year of the evaluation. HLF people outcomes cover five areas:

- $\quad$ people will have developed skills

- $\quad$ people will have learnt about heritage

- $\quad$ people will have changed their attitudes and/or behaviour

- $\quad$ people will have had an enjoyable experience

- $\quad$ people will have volunteered time.

Respondents to the Grant Recipient Survey were asked to provide their views about the types of outcomes their project had achieved. This included seven types of outcome for people. Respondents were asked to identify any outcome that they felt they had achieved and up to three main outcomes from their project. The responses are summarised in Figure 4.2. This shows that the most commonly identified outcome, and the most frequently identified main or most important outcome, was improving people's understanding of the FWW. Other commonly identified outcomes included changing the way people think about the war and its impact on the community, providing people with something new and rewarding to do, and increasing the number of people engaging with the heritage of the FWW. 
Figure 4.2: Outcomes for people identified by grant recipients

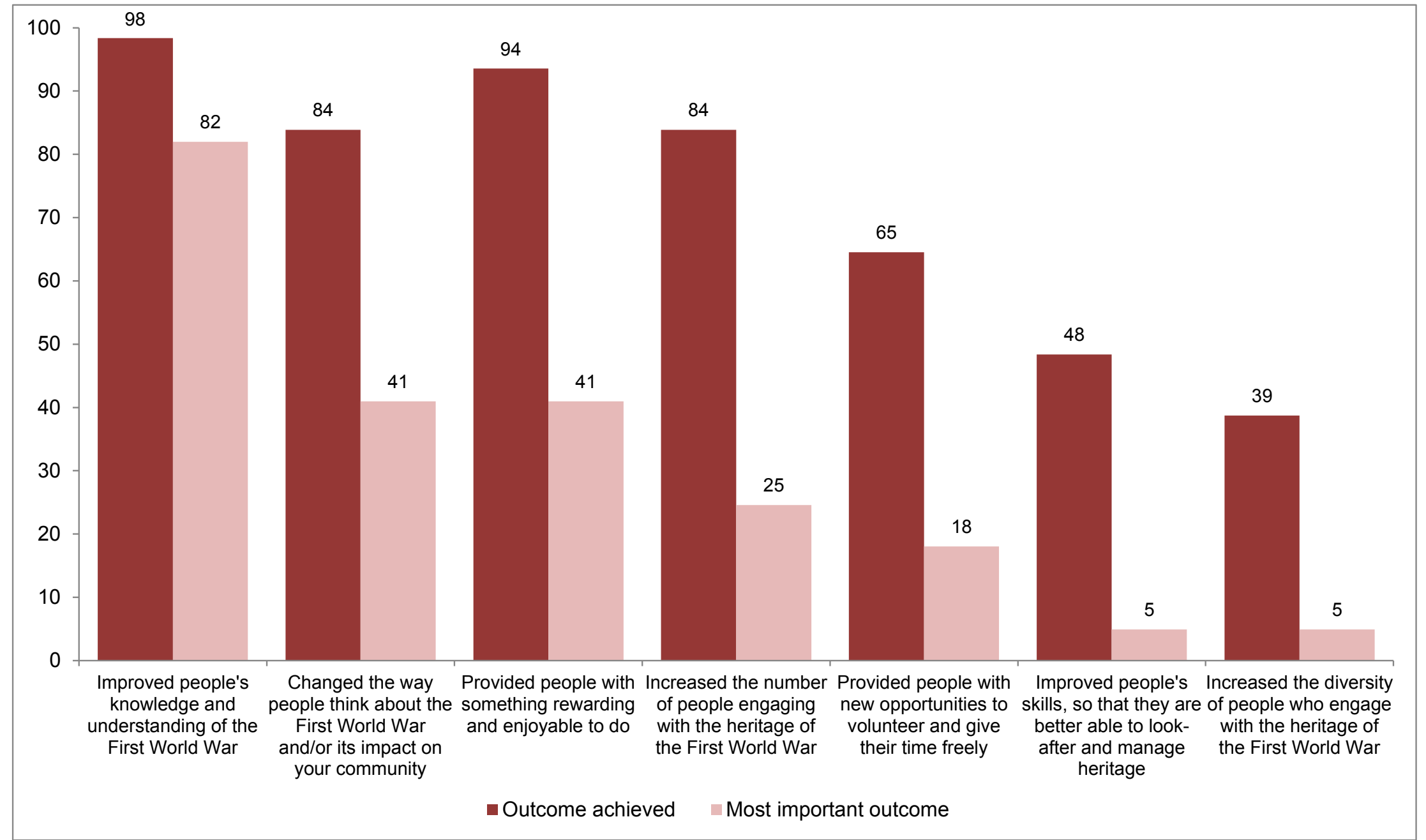

Source: Grant Recipient Survey (2014-15)

Base: All valid responses $(n=61)$ 


\subsubsection{People will have developed skills}

The chart above shows that 48 per cent of projects aimed to improve people's skills, so that they are better able to look after and manage heritage, although only five per cent included this as a 'central' aim of their project.

All respondents, excluding visitors, were asked to what extent they had improved their skills in a number of areas through their involvement in HLF-funded FWW Centenary projects. Figure 4.3 below shows the number of participants stating that at least 'some improvement' had been made to the skills listed. Information management and communication skills were the skills most frequently identified as experiencing some improvement. Responses to this question are encouraging, although the picture will become clearer as more responses are gathered.

Figure 4.3: Skills where respondents have experienced an improvement

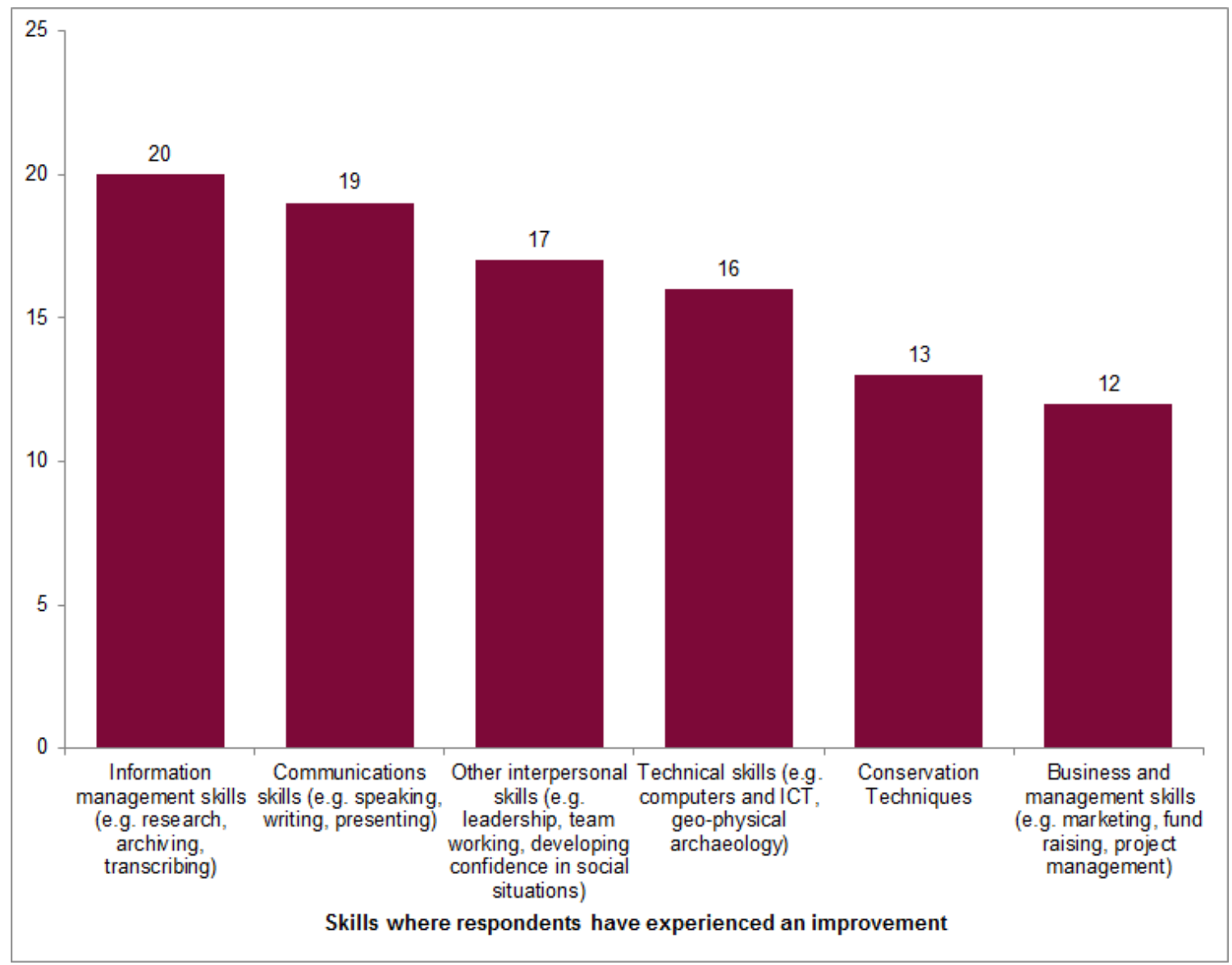

Source: Participant Survey (2015)

Minimum Base: All valid responses $(n=33)$

The development of interpersonal skills was perhaps the strongest theme among case study respondents, coming through strongly in each of the five projects. In Brierfield, the five young people participating in the project were "transformed" by their involvement with the project: "they've grown up, they've matured a lot, we've seen them flourish" (Project lead). Each of the participants interviewed for this case study was able to talk about their own personal development as a result of their involvement with the project. 
Similarly in Inverness participants derived a number of benefits from increased selfconfidence:

'It's the first thing that I was involved in that is also a massive scale thing....there's so many stages to it. It's made me feel more confident I guess because I had to audition to get in....and then meeting new people and realising that I could get to know them and work with them, making new friends' (female, young person).

Developing research skills was also a strong theme in the case studies, with respondents in four case studies outlining their importance to the respective projects. In Flintshire, the four volunteer researchers referred to the research skills they had developed through their involvement in the project. They had all received training from the project leads, as well as taking part in training days at the Records Office.

In all then, although the survey response levels are too small at this stage to make any clear conclusions with regard to skills development, these responses combined with case study evidence suggest that there is at least good potential for skills development through activities, particularly in relation to research and conservation, but also (importantly) as a means for developing interpersonal skills and selfconfidence. These softer elements of personal development are picked up again when considering the additional people outcomes not captured in the HLF outcomes framework below.

\subsubsection{People will have changed their attitudes/behaviour}

81 per cent of Grant Recipient Survey respondents felt that their project had led to a change in the way the people thought about the FWW and for 42 per cent this was one of the most important outcomes. This is reinforced by the Participant Survey, with 24 participant respondents (out of 30 respondents) saying that their engagement with the FWW Centenary activities had 'challenged' them and had been thoughtprovoking, suggesting that projects were successful in challenging participants' existing attitudes. Similarly, visitors and participants were asked whether their experience of the project they visited or were involved in had given them a greater understanding and respect for other people and their cultures. They were asked to give a response to this question on a scale of 1 to 10 where 10 is 'much greater' and 1 is 'no change at all'. Eight out of the 15 visitors responding to the survey gave a score of 7 or more while 12 out of the 15 participants responding gave a score of 7 or more.

Qualitative material brings some nuance to this picture. In Brierfield, for example, participants reported both positive and negative consequences of the project challenging their and others' beliefs and prejudices. The participants were able to point to changes in both attitudes and actions that they have taken as a result. As noted above, they each had a much more in-depth understanding of the FWW, and of the 'reality' of war more generally. They had developed a much more nuanced perspective on the FWW which had led them to consider the extent to which others also understood the profound nature of armed warfare and its relation to lives today. One example of this can be seen in participants' reflections on war-based computer games and action they took to raise awareness about this in their school:

Some kids they play Black Ops and GTA, they can just pause it and they don't realise, once you're dead, you're dead. And some people at school now realise that war isn't just like these games. When you're playing Call of Duty you can pause it and get something from the fridge, we made them realise that you can't do that in real war. (OWW1 Participant 2) 
Changing perceptions was also a key challenge for the On The Brink project in Ballymena. The project lead described the importance of the project in 'myth busting' as part of this challenge:

I think I've been harping on for so long about these interconnected histories [between communities], the volunteers get it, it's all registered with them and their appetite for learning and identifying these connections, it's just grown and grown and grown. So that has changed their attitudes most certainly, their attitudes to the past and these histories, their ownership of these histories (Project lead)

The project worked to develop understandings focused on shared understandings about the impact of war and conflict on lives in the past and lives today. The project lead made particular efforts to engage community groups from both Unionist and Nationalist communities, and a key project aim is to present balanced historical accounts within the project exhibits:

I think we've myth-busted a lot, their inherited attitudes and understandings of the First World War (Project Lead).

Volunteers referred to the ways in which they had developed their knowledge and understanding about their shared history, and felt that they now knew a lot more about the FWW both in the context of Northern Ireland, but also beyond:

Seriously different thinking on everything, you know, about how everything in Northern Ireland... you know, some of the stuff that's still going on at the minute is, you know, part of that whole process of what was going on at that time. (Volunteer)

Visitors and participants were also asked if they had felt motivated to do something related to their experience of the project they visited or were involved in. They were asked to give a response to this question on a scale of 1 to 10 where 10 is 'very motivated' and 1 is 'not motivated at all'. Nine out of the 15 visitors responding to the survey gave a score of 7 or more while seven out of the 14 participants responding gave a score of 7 or more. Case study material helps shed further light on this. A number of FWW Centenary projects involved promoting action to change perceptions in relation to the role of non-British soldiers in the FWW, in particular people of Black and Asian heritage. For example the Our World War One project in Brierfield centred on action to engage with the local Asian community (see community outcomes, below).

Overall, then, there was evidence to suggest that projects could successfully challenge individuals' attitudes and move towards behaviour change, even in relation to deeply-held attitudes and sensitive cultural differences and stereotypes.

\subsubsection{People will have learnt about heritage}

Learning about heritage, and specifically the FWW was well-evidenced. This was a project outcome for 98 per cent of respondents to the Grant Recipient Survey, 84 per cent of whom said it was one of the most important outcomes. This is reinforced by responses to the Participant Survey. Respondents were asked to rate the gains they had made in knowledge and understanding following their involvement in projects across a number of areas. Gains were reported across all areas listed, suggesting people had learnt about heritage across a variety of different aspects related to the First World War Centenary. The most popular of these were as follows:

- People from the UK who served abroad or at home (43 respondents); 
- $\quad$ Local people (43 respondents);

- The impact of the FWW on the local area (43 respondents);

- The lives of people commemorated on war memorials (40 respondents);

- War memorials (38 respondents).

This is given some depth by reference to the case studies. In each of the five projects learning about the FWW was a central outcome of the project. For young people in particular projects acted as means of beginning to engage with the FWW as a subject, often for the first time. In Inverness, for example, young people involved in the project emphasised how they had increased their existing knowledge, or gained new insights into the FWW local history:

The FWW is a very well documented event from history but you don't get to see either the more personal or more toned down side to it, the family life that they were leading' (AWH participant 1)

The strong connection with the material that they unearthed was attributed to the personal connection that they had with it, e.g. 'history in school would cover the political aspects of the FWW, but not the personal stories'. As a result, young people expressed feelings of empathy, more interest in the FWW subject, and reported a greater impact on them than was possible when learning history at school:

'You could empathise with the characters, it felt much more human. It had a much bigger impact than anything you could learn by the desk' (AWH participant 2)

'Much more of a human element than you find out about at school' (AWH participant 1)

An important part of this learning was about situating the 'grand narrative' of the FWW within specific events and places. For instance, most of the visitors to the Somerset Remembers exhibition interviewed during the case study visit reported that they had not participated to acquire new knowledge about the First World War in general, and felt that they had not learnt anything new about it. On the contrary, however, many of the respondents gave examples of what they had actually learnt about the FWW "from a Somerset perspective" (SR visitor 1). They gave responses suggesting they had learnt more about the history of Somerset, for example, two female visitors claimed that they learnt more about the involvement in the First World War of individual men and women as well as families from Somerset. Another respondent stated that learning about the war "at home" made her realise "how it changed people's lives tremendously... in the way people worked and moved" (SR visitor 2).

\subsubsection{People will have an enjoyable experience}

One of HLF's outcomes is for people to have had an enjoyable experience. All respondents, except those who only received training, were asked how much they had enjoyed either volunteering, taking part or the work of a project. They were asked to give a response to this question on a scale of 1 to 10 where 10 is, 'enjoyed a great deal' and 1 is 'not enjoyed at all'. All respondents gave a response of 5 or above with 42 out of 48 respondents giving a score of 9 or 10 . Across each of the case studies, respondents referred to how much they had enjoyed taking part in projects. In many cases, however, this went further, with a deep sense of emotional enrichment taking place: this is outlined in section 4.4.1, below. 
As such, although the young people greatly enjoyed the various trips and conducting research, it is worth noting the deeper emotional impact of the project. People will have volunteered time

\section{People will have volunteered time}

One of HLF's outcomes is for people to have volunteered time. There was a strong emphasis on volunteering across projects, partly reflecting the reality that projects required volunteers in order to be effectively delivered. The key points on this are covered in Section 3, above, but to briefly recap, 95 per cent of respondents to the Grant Recipient Survey said that their projects involved volunteers. This amounted to almost 2,600 people providing more than 16,000 hours of their time willingly and free-of-charge.

Looking to early results from the Participant Survey, the mean number of hours per week volunteers indicated they had volunteered on projects since they started was four hours per week (from a relatively small sample of 16). The median was three hours per week with the minimum number of hours volunteered one hour per week and the maximum 20 hours per week.

\subsection{Outcomes achieved beyond the HLF outcomes framework}

\subsubsection{Emotional enrichment}

The HLF outcome framework includes an outcome on the enjoyment derived from heritage projects. This was well-evidenced for FWW Centenary projects, as discussed above. Importantly, however, enjoyment is just one element of a potential broader impact on the emotional enrichment of participants. The case study material illustrates this well. In Somerset visitors implied that the exhibition, which detailed the war stories of individuals from the area had touched them emotionally because of how personal it was. One visitor commented that he found the exhibition "touching", seeing "things people have written and to see the uniforms" (SR Visitor 3). The experiences of those involved in the Our World War One project take this further. Every person involved in the project reported having greatly enjoyed their participation in the project.

It's the best project l've worked on. (OWW1 Project lead)

It was a joy, they're a great bunch. One of the best projects l've been involved with ... It's been very rewarding to sit and talk to them and see them understanding and passing on the message to others. (OWW1 Volunteer)

But the emotional impact of the project went further than enjoyment: the project was very emotionally enriching for the student participants. For instance, they talked about how they were affected by their visit to the FWW cemeteries in Belgium and France:

It was really emotional. Really touching. That so many people died ... It upset me, because when you get there there's so many people that've died and that's only one group of the people that died, and there are so many other cemeteries with people that died. But it makes you realise the respect that people have for them, because it's all tidy and looked after and it makes me feel proud to say my country did that and other people respect that. (OWW1 Participant 1)

It's also astonishing; the number of people, it's not just hundreds it's millions... the number that died in the war. (OWW1 Participant 3) 
I thought it was just English people but there were three Germans at the back. And their graves weren't like ours. The British graves were all curved and nice and theirs were all dull and stone and like squares. It just looked a bit scary. And we went to the German cemetery and it wasn't the same - it was all dull ... I was pretty emotional because I was born in Germany ... it shouldn't be different because of where they were from (Participant 4)

\subsection{2 mental wellbeing}

In addition to emotional impacts the evaluation also considered the ways in which mental wellbeing was affected by taking part in projects. These outcomes are not covered by HLF's outcomes framework, but are an important means of understanding the wider benefits of volunteering and participation.

A series of questions around wellbeing were asked to Participant Survey respondents who had volunteered in some capacity. Volunteers were asked about how they felt recently and whether this differed to how they felt before they got involved with projects. ${ }^{11}$ Again, the number of respondents is small at this stage, but the results are worth including here to provide an indicative sense of change. Figure 4.4 shows how in most cases there had not been significant change across the four areas covered by the survey. A small number of respondents across each of the measures did however indicate that they felt less positive before engaging with projects. Nonetheless, with only a small number of responses to the survey at this stage it is hard to read much into these results: this will be something to monitor moving forward.

\footnotetext{
${ }^{11}$ This series of questions is also being used in HLF's Our Heritage evaluation, and is based on Office for
} National Statistics national wellbeing indicators. 
Figure 4.4: Wellbeing indicators

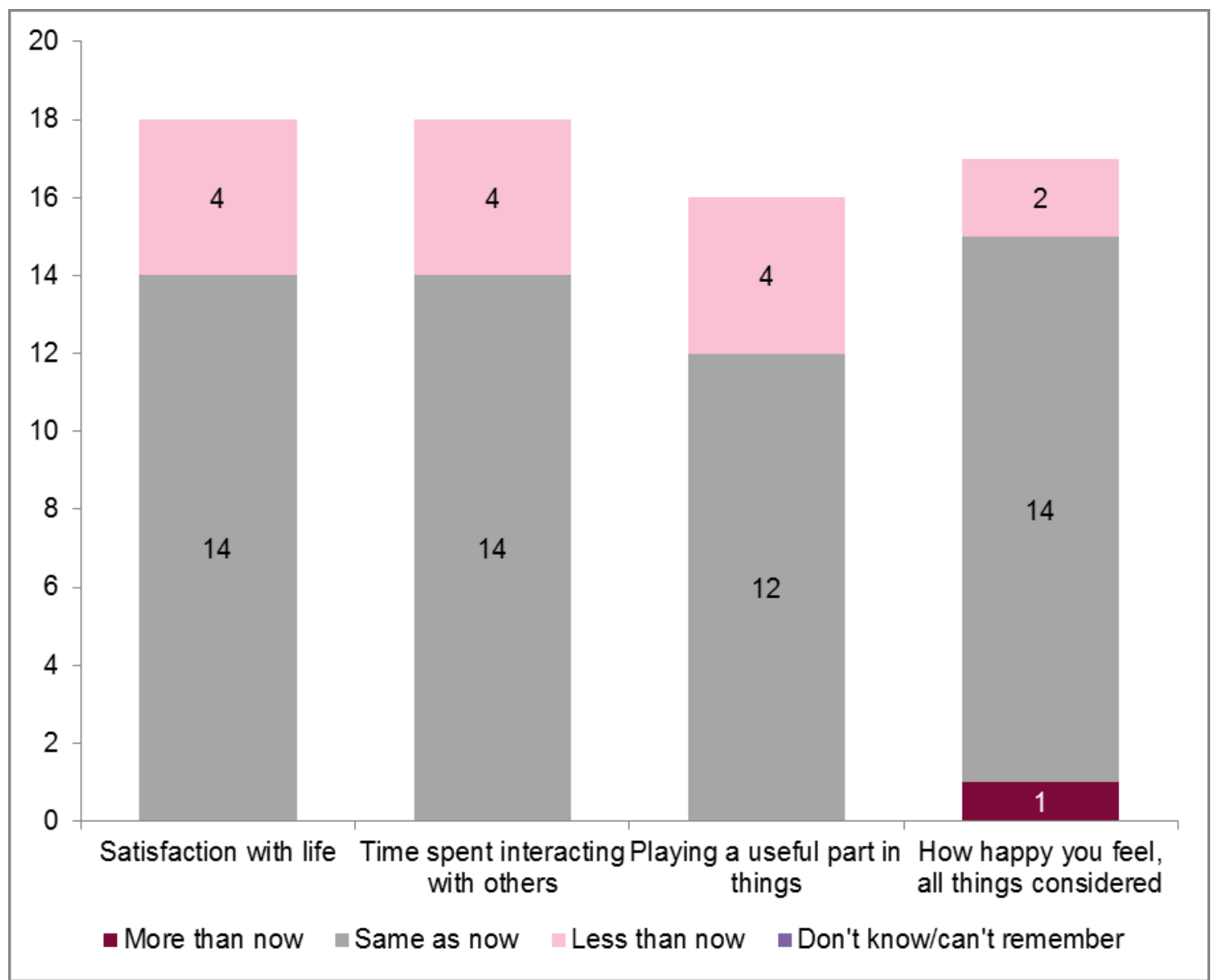

Source: Participant Survey (2015)

Minimum Base: All valid responses $(n=16)$

\subsection{Outcomes for communities}

The HLF outcomes framework includes five community outcomes. These are as follows:

- environmental impacts will be reduced;

- $\quad$ more people and a wider range of people will have engaged with heritage;

- your local area/community will be a better place to live, work or visit;

- $\quad$ your local economy will be boosted;

- your organisation will be more resilient.

Projects have been able to some provide evidence across each of the outcomes areas, with the exception of reduced environmental impacts (which was partly to do with the focus of the evaluation questions). For this reason environmental impacts are not discussed in this report.

\subsubsection{More people and a wider range of people will have engaged with heritage}

HLF seek to engage more people and a wider range of people with heritage. In addition to qualitative responses, this is tracked in the evaluation through the following survey questions: 
- Three questions in the Participant Survey asking: whether they had visited HLFfunded projects before; whether volunteers had previously volunteered with the organisation delivering the HLF-funded FWW Centenary activity; and demographic information about participants.

- Two questions in the Grant Recipient Survey asking whether activities had increased the number of people engaging with the heritage of the FWW, and if they had increased the diversity of people who engage with FWW heritage.

In terms of engaging more people, 84 per cent of Grant Recipient Survey respondents said that this was an outcome of their project. Of the 15 visitors who responded to the Participant Survey, seven had not visited a HLF-funded project before, three had and five did not know. Of the 18 volunteers who responded to the survey, 10 stated that they had started volunteering when the project had started. Although small in number, these responses indicate that there are potentially large numbers of people engaging with HLF projects who have had no involvement before. However, of course they may have been engaged with heritage in other ways.

The question of whether a wider range of people have engaged with heritage as a result of FWW Centenary activities is less easily answered at this stage, especially without existing baseline data on the types of people that currently engage with heritage projects. ${ }^{12}$ Around two-fifths (39 per cent) of Grant Recipient Survey respondents said that they had achieved this outcome - the lowest percentage across the seven outcome-related questions in the survey - and only five per cent of respondents felt that this was one of the main or most important outcomes of their project. The demographic information provided by Grant Recipient Survey respondents gives an indicative understanding of the profile of participants: as discussed in Chapter 3 the data suggests that engaging with people from some black, Asian and minority ethnic backgrounds, and young people aged 18-25 might be proving a challenge for projects (when compared to the overall UK population profile).

Case study material suggests that some projects have been more proactive in attempting to engage different groups than others, but there was evidence projects could be successful in widening participation. The Brierfield Our World War One project is a good example in this sense, both through working with participants from a range of different backgrounds and by successfully engaging with members of the local Asian population, in particular through working with two local mosques (see Section 4.5.2, below). Similarly one survey respondent outlined their successes in engaging different demographic groups:

The greatest successes have been the two community exhibitions at libraries as this has enabled a range of participants from different age groups and ethnicities to be involved in the project through providing objects and stories for the exhibitions, reminiscence sessions and involvement in craft workshops creating items relating to the exhibition. Other successes included a museum talk about Sikh Troops in WW1 that had a high proportion of BME attendees. (Survey respondent)

\subsubsection{Your local area/community will be a better place to live, work or visit}

Capturing project impacts across whole communities can be difficult to achieve, especially when 'community' refers to a place with potentially thousands of residents: any effects are easily diluted by a sea of other activities and influences. Nonetheless, perceptions from grant-recipients, participants and visitors was that projects were

\footnotetext{
${ }^{12}$ The evaluation of the Heritage Grants programme in 2012 does include demographic profiles of visitors, but Heritage Grants account for only a small proportion of FWW grants, and are not directly comparable to the majority of projects, which are smaller projects largely funded through FWW: Then and Now.
} 
making some difference to communities. This inevitably varied, however, as the early responses to the Participant Survey shows.

Visitors and participants were asked how much they thought the project they either visited or were involved in had helped the local community (for example, by providing a greater sense of identity or understanding, increasing interest or pride in the local area and its heritage, improving bonds between different sections of the community).

Respondents were asked to give a response to this question on a scale of 1 to 10 , where 10 is 'helped the community a great deal' and 1 is 'not helped at all'. Impressively, 19 out of 30 respondents gave a response of eight or more and 29 of the 30 gave a score of over 4 .

These positive findings are borne out by the case studies, with each project able to demonstrate some level of impact on their local area. This impact moves beyond simply the importance of carrying out community-focused activities: it suggests that there is clear added value in the heritage dimension of projects, with the FWW a particularly powerful vehicle for understanding shared histories and deepening attachments to local communities. This was discussed in Flintshire, where respondents talked about the importance of communities learning more about their past, and how this helped to develop a sense of community.. In Brierfield, for example, there was a feeling that the project was starting to change perceptions about the area, and break down some barriers between different population groups. One of the project leads explained how events at local mosques and FWW commemoration events on the $4^{\text {th }}$ August and $11^{\text {th }}$ November had really worked to engage the local Muslim population and get people from different populations mixing:

..we got a nice representative mix right across the community, and we also got a few members of the Asian community to come along to pay their respects. Which I think was a surprise, to the people who would usually be there. .... And also at Remembrance Sunday, there was a bigger turnout than there's ever been. At least 100 people came. And l'd say it's probably 70 per cent White British and 30 per cent Asian people, but they're people who haven't even attended before, and that's from both Asian and White British sides. (OWW1 Project lead)

Creating more liveable communities is inherently challenging, and many case study respondents reported thatengaging different communities within the local area involved investing significant time and effort. The extent to which projects are positioned to achieve this varies significantly. But perhaps the most rewarding of projects will be those that attempt to meet this challenge as a central focus of their activities.

\subsubsection{Your local economy will be boosted}

The evaluation has not attempted to capture quantitative data relating to impacts of FWW activities on local economies: this would be a sizeable task in itself. This was discussed in the case studies, but there was little available evidence. Since the majority of projects are relatively small this is unsurprising. Intuitively, however, impacts on people and communities, the potential for increased numbers of people visiting areas to take part in activities and the direct monetary provision from HLF and the further financial resources leveraged by projects as a result of this funding will have a combined impact (albeit often small) on local economies. 


\subsubsection{Your organisation will be more resilient}

Grant Recipient Survey respondents were asked a number of questions about the impact of HLF FWW funding on their specific FWW project and on their organisation or group has whole. Figure 4.5 provides an overview of the importance of HLF funding for their First World War Project while Table 4.2 provides an overview of its impact on the capacity of organisations.

\section{Figure 4.5: Importance of HLF funding to funded projects}

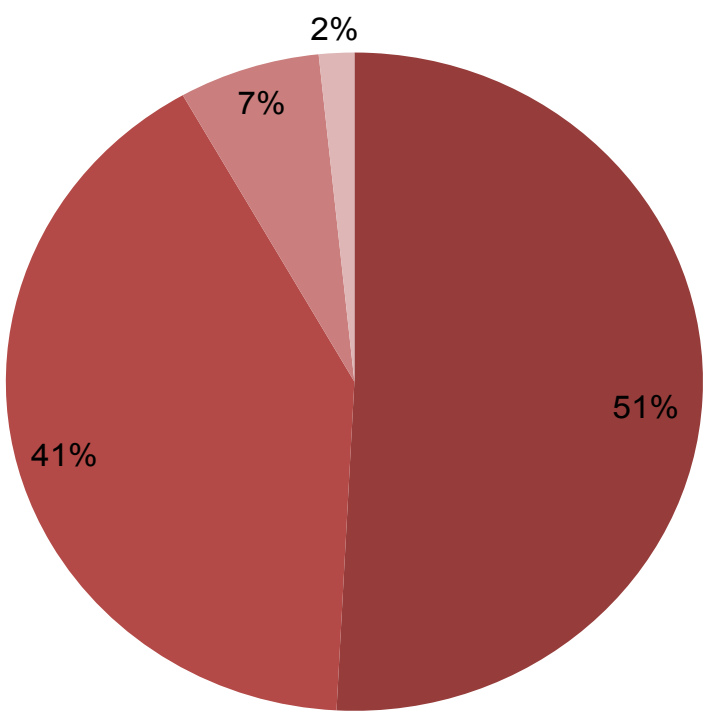

- The scope of the project would have been reduced to take account of the reduced funding available

- The project would not have gone ahead at all

- The project would have been delayed whilst alternative sources of funding were sought

The project would have gone ahead as planned using alternative sources of funding

Source: Grant Recipient Survey (2014-15)

Base: All valid responses $(n=61)$

Figure 4.5 demonstrates that for a majority of projects HLF funding was of vital importance: 51 per cent said that the scope of their project would have been considerably reduced without the funding and 41 per cent said it would not have gone ahead at all. In contrast only two per cent said they would have been able to progress as planned with alternative sources of funding. 
Table 4.2: Impact of HLF First World War funding on the wider capacity of funded projects

\begin{tabular}{|l|r|r|}
\hline & $\boldsymbol{n}$ & $\boldsymbol{\%}$ \\
\hline Engage with more people, and a wider range of people & 51 & $86 \%$ \\
\hline Deliver projects of a similar scale and scope in the future & 48 & $81 \%$ \\
\hline Focus on different aspects of First World War heritage & 44 & $75 \%$ \\
\hline Attract grant funding for new projects & 35 & $59 \%$ \\
\hline Fundraise for new projects & 24 & $41 \%$ \\
\hline Deliver larger heritage projects in the future & 18 & $31 \%$ \\
\hline
\end{tabular}

Source: Grant Recipient Survey (2014-15)

Base: All valid responses $(n=59)$

Table 4.2 highlights the wider importance of HLF funding for many projects. Nearly nine in ten said it had enabled them to engage with more people and more than fourfifths said it had improved their capacity to deliver similar projects in the future. Similarly, three-quarters said it had enabled them to focus on different aspects of First World War heritage and three-fifths said it had improved their capacity to attract funding for new projects from other sources.

\subsection{Outcomes achieved beyond the HLF outcomes framework}

\subsubsection{Increasing capacity by engaging with other organisations}

Although not covered in the HLF outcome framework, a theme cutting across each of the outcome areas is the achievement of increased heritage capacity more generally through the development of partnerships with other organisations. At a local levelthere was good evidence of projects developing partnerships with a range of different organisations and FWW projects were seen as "really important" (OWW1 Project lead) in helping to engage with other organisations These included the following examples from case studies:

- The Somerset Remembers project formed a number of partnerships to support the project practically and financially, including: the Somerset Military Museum Trust which contributed collections; The Western Front Association; Museums in Somerset Group; The Friends of Somerset Archives; and a number of schools. These organisations had various levels of involvement in the project from working on the exhibition, to the opening of the exhibition etc. Among other heritage organisations there was an immense interest in the First World War, which led to a wealth of work within the county.

- $\quad$ Flintshire War Memorials engaged in partnerships with local schools, supporting their WW1 memorial projects via the web resource. This project developed a good working partnership with the local Records Office.

- In Brierfield, the Our World War One project had successfully worked with a number of organisations in the local area. Most notably they had developed a strong relationship with the British Legion and two local mosques, but also local churches, the community library, a local history group, a historian at Lancashire County Council and (more recently) another HLF Then and Now project involving the Bury Fusiliers. 
One area in which projects appeared to be doing less at this stage was working with other organisations to share good practice and challenges faced in the delivery of FWW projects. According to one project lead, projects funded by the HLF“... perhaps aren't talking to each other as much as they could have been".

This is something to monitor as the evaluation progresses into Year 2.

tThe extent to which projects have engaged with the five AHRC-funded Engagement Centres is also relevant to this outcome.These centres have been set up with a range of objectives, including that of providing HLF's FWW Centenary projects with support.. Although almost one in three respondents said they were aware of the Centres far fewer - only three out of the 60 respondents - had actually received support from them. This may be a reflection of the fact that the Centres are still being established rather than illustrative of a wider lack of engagement by HLF grantees. The Grant Recipient Survey will continue to monitor this engagement over the next year after which a clearer picture will emerge.

\subsection{Conclusions}

A continual refrain of the evaluation at the end of Year 1 is that 'it is too early to tell' across a number of outcome areas, because the survey data are still relatively limited. Yet, when combined with the qualitative data from case studies, the data do suggest that as a combined whole, FWW activities are achieving outcomes under almost every outcome area.

People outcomes are particularly well-evidenced and appear to be most relevant to the majority of projects, in particular in relation to learning about heritage and developing new skills.

While still evident, outcomes for heritage and communities are less pronounced at this stage. There are different reasons for this. One is that some outcomes were seen as less relevant to the majority of projects at the outset and so have not been covered in the evaluation: for instance, impacts on the local economy and environmental impacts. In other areas the evaluation may need adapting slightly to capture more data, for instance heritage will be better managed. And the datasets are still small across all outcome areas. Taking these factors into consideration, it is difficult to say definitively that outcomes are not being achieved where they should be. However, there is some evidence to suggest that wider participation in heritage could be given greater priority by projects, which might include promotion and guidance from HLF (and indeed HLF have already indicated that they are working towards doing this). Even in this instance, further exploration in Year 2 will be necessary in order to more confidently assess success in this outcome area.

Taking this forward, three areas in particular are worth further investigation in Year 2:

- whether projects are achieving outcomes under the "heritage will be better managed' heading

- the extent to which 'wider' engagement is being achieved through FWW projects;

- the extent to which AHRC-fundedEngagement Centres are engaging with projects, and any outcomes associated with this;

- the extent to which projects are working to develop outcomes for communities as 'better' places to live, work and visit.

- As a cross-cutting issue, the extent to which projects are engaging with other FWW projects to share good practice and learning remains unclear, with early 
evidence suggesting that there might be more to do to promote these types of engagement..

The report now turns to consideration of the specific aims set out for the Centenary activity. This involves some synthesis of evidence already presented, as well as introducing new analysis from the surveys and case studies. 


\section{What progress has been made on HLF's Centenary aims?}

This chapter considers the progress made to date on HLF's FWW Centenary activity aims. These fall under two broad categories, as follows:

1. To fund projects which focus on the heritage of the First World War and collectively:

- create a greater understanding of the First World War and its impact on the range of communities in the UK;

- encourage a broad range of perspectives and interpretations of the First World War and its impacts;

- enable young people to take an active part in the First World War Centenary commemorations;

- leave a UK-wide legacy of First World War community heritage to mark the Centenary;

- increase the capacity of community organisations to engage with heritage, and to raise the profile of community heritage.

2. To use the Centenary projects that HLF funds to communicate the value of heritage, the impact of their funding and the role of HLF.

As noted, this evaluation focuses on the aims falling under the first category.

Overall there is evidence of some progress against each of these aims, although once more, these have to be caveated with the fact that the evaluation remains in its early stages. Each of the aims is considered in turn below.

\subsection{Create a greater understanding of the FWW and its impact on the range} of communities in the UK

The first clause of this aim is relatively well-evidenced. As discussed under outcomes for people, above, FWW Centenary activities have been successful in improving knowledge and understanding of the FWW. This was evidenced across a number of survey questions. To summarise:

- $\quad 98$ per cent of respondents to the Grant Recipient Survey felt that their project had improved people's knowledge of the FWW; and 82 per cent saw this as one of the most important outcomes of the project.

- 84 per cent of respondent to the Grant Recipient Survey felt that their project had changed the way that people think about the FWW and/or its impact on their community.

- Participants reported having gained knowledge about the FWW, across a range of subjects, including impact on their local area (43 respondents). 
The case study material reinforced this, with learning about the FWW a key outcome for each of the five projects visited.

Understanding of the FWW's impact on the range of communities in the UK is slightly harder to disentangle. What can be said is that HLF's funding reached every part of the UK (see Chapter 3, above). Further investigation of the types of geographic communities (that is, those bound by place) being reached would help to take this further, and might be something to consider for Year 2 of the evaluation.

In terms of non-geographic communities, detail on the demographics of participants suggests that different ethnic groups are also being reached, although there is tentative evidence that some black, Asian and minority ethnic groups are less wellengaged at this stage. Case study material outlines both the challenges faced in engaging a range of cultural communities, as well as the possibilities for success: the Brierfield Our World War One project being a case in point.

\subsection{Encourage a broad range of perspectives and interpretations of the FWW and its impacts}

There is evidence that FWW Centenary activities are allowing individuals to develop understanding of many different elements of the FWW. The Participant Survey, for example, suggested that people were learning about a wide range of issues. At the same time, comparison of the aspects that respondents most commonly reported as having improved their knowledge on with those least commonly cited is instructive. Table 5.1, below, shows the six most commonly reported areas of increased knowledge against the six least reported areas. It highlights, for example, that less than half as many people had learned about objection to the war as had learned about war memorials. This is not to say that one or the other of those areas is intrinsically more valid, but that certain elements of the FWW have been better covered by projects than others.

Table 5.1: Most and least common gains in knowledge

\begin{tabular}{|l|c|c|c|}
\hline Most common responses & Responses & Least common responses & Responses \\
\hline $\begin{array}{l}\text { People from the UK who } \\
\text { served abroad or at home }\end{array}$ & 43 & Beliefs & 19 \\
\hline Local people & 43 & Industry & 19 \\
\hline $\begin{array}{l}\text { The impact of the war on the } \\
\text { local area }\end{array}$ & 43 & Sport in wartime & 17 \\
\hline $\begin{array}{l}\text { The lives of people } \\
\text { commemorated on war } \\
\text { memorials }\end{array}$ & 40 & Animals in war & 16 \\
\hline War memorials & 38 & Dissent/objection to the war & 16 \\
\hline War on the ground & 36 & Faith communities & 14 \\
\hline
\end{tabular}

There was recognition within HLF that there might be a need to work more on this aim:

Next year we've decided we will give some more focus to showing how you can bring a diverse perspective and we'll give some more focus to showing people that within their own project they can talk about interpretations of history, about stories that have grown up and maybe about someone else's perspective, we'l highlight some of the ones where people are working very consciously with different groups and comparing and some of that's about comparing a 
perspective outside the UK or comparing a perspective of a community in the UK with a different community in the UK. (Internal Stakeholder)

Alongside communication and promotion by HLF, achieving this aim might also benefit from improved engagement with the AHRC Engagement Centres (as discussed in Section 4, above), which have this aim as an objective in the form of inspiring projects to explore new avenues. But it is also about recognising that many projects represent a first step into developing an understanding of the FWW; the next stage was to challenge those projects to then move on to take things further into more challenging or exploratory realms (as also reflected in stakeholder interviews). This was raised as a possibility in stakeholder interviews, and qualitative survey material also shows that a number of respondents were looking to build on their experiences of delivering a FWW Centenary project by applying for further funding to take the projects further. Furthermore, projects taking place early on in the FWW Centenary were perhaps more likely to be focusing on more 'obvious' local themes that relate to the overall popular appeal of the FWW Centenary in the context of the range of media coverage and national events taking place in 2014 (also raised in stakeholder interviews). As a result there might be more scope for greater numbers of projects focusing on different aspects of the FWW to emerge over the course of the Centenary period.

\subsection{Enable young people to take an active part in the First World War Centenary commemorations}

HLF define young people as those aged between 11 and 25. The Grant Recipient data suggested that around 9 per cent of participants fell into this category. This compares to 18 per cent of the UK population within this age group, suggesting that there is further work to be done to ensure that young people are able to actively participate in FWW Centenary activities.

However, considering a different age range around those that are likely to be in fulltime education shows a more positive picture: 18 per cent of participants were aged six to 18 compared to 16 per cent of the UK population. Those aged six to 10 were particularly well represented (11 per cent, compared to six per cent of the UK population). It is also clear that many projects were seeking to engage with schools: 49 per cent of Grant Recipient Survey respondents said that their project had received visits from schools and colleges, and 49 per cent also said that they had carried out outreach work in schools and colleges. All of the case study projects were either working directly with or engaging with schools in some way and qualitative survey material also brought out some examples of successes in this regard: in responding to an open question asking respondents what the biggest success of their project had been, a number referred schools as offering a good 'way in' for projects in terms of engaging young people, and these data suggests that projects are making good use of this method of engagement.

\subsection{Leave a UK-wide legacy of First World War community heritage to mark the Centenary}

Legacy is a difficult term to pin down and there are different ways in which this aim might be achieved. Part of this might be about long-term impact and the extent to which HLF's funding leads to activity over a period of years beyond the end of the FWW Centenary: it is, clearly, too early to consider this. Interviews with internal and external stakeholders elicited a definition of legacy in this context as, "leaving a historical record of what has the Centenary meant to people and what has happened" (Internal stakeholder) 
The use of Historypin to document a project might be seen as a means of creating a legacy of projects. 42 per cent of projects (of those that responded to the grantrecipient survey) had already created project pages on the website, suggesting that this is happening to some degree, at least. Further to this, HLF and the British Library have also developed a partnership to create a First World War Centenary Special Collection in the UK Web Archive. The collection will include snapshots of the First World War Centenary websites funded by HLF and will be preserved and made publicly accessible online by the UK Web Archive.

Alternatively, we might look at the passing down of knowledge, and engagement of young people in the hope that they will carry stories of the FWW Centenary onto future generations. As discussed in Chapters 3 and 4 there is clear evidence that young people are being engaged in projects. Finally, the UK-wide element of legacy is discussed above: projects are taking place in good numbers right across the UK.

\subsection{Increase the capacity of community organisations to engage with heritage, and to raise the profile of community heritage}

This aim relates specifically to capacity-building. There is clear evidence that HLF funding has increased capacity across a number of domains. It is possible to look at the data collected relating to the impact of HLF funding on organisations' long-term sustainability and capacity to deliver projects; and also at the development of new partnerships or consolidation of existing partnerships as a means of creating longterm institutional capacities for FWW community heritage. There is evidence that both of these outcomes are being achieved, albeit to varying degrees.

100 per cent of Grant Recipient Survey respondents felt that HLF funding had positively impacted on the capacity of their organisation in some way with many respondents saying that it would help enable them to deliver similar (81 per cent) or larger (31 per cent) projects in future.

There was also some evidence that partnerships were being developed to build a longer-term commitment and ability to deliver FWW-related projects. On the basis of the evidence collected to date this appeared to be taking place mostly on an ad hoc basis in that it tended to be instigated by individual projects, although HLF had been instrumental in bringing together a number organisations at the individual project level: for instance the regional team in the North West had suggested that the Brierfield project visit another local project. However, the larger FWW Centenary 'infrastructure' such as the AHRC Engagement Centres were not yet at the point of having made impact on individual projects.

There is also an additional dimension to understanding improved capacity which would consider the extent to which community organisations are engaging with heritage having not previously done so. HLF project data shows that 65 per cent of FWW Centenary projects were first time applicants. The case study materials give some further evidence on this, showing the different ways in which capacity can be developed through Centenary projects, as follows:

- The Flintshire War Memorials project developed the capacity of an existing FWW-related heritage group.

- $\quad$ Although not their first HLF project, this was the first time Brierfield Action in the Community and Participation Works - the organisations leading the Our World War One project - had carried out a FWW project. It had motivated them to explore carrying out another FWW project in future.

- On The Brink in Ballymena was part of a larger programme of work looking at events in Northern Ireland's 'Decade of Centenaries' from 2012-2022, led by an 
organisation with previous experience of delivering heritage projects. The funding allowed the project to go ahead on a larger scale than would otherwise have been the case

- Somerset Heritage Centre, delivering the Somerset Remembers project, had existing experience of delivering heritage projects, including for HLF. The funding had potentially increased capacity to deliver heritage projects in future, however.

This can by no means be taken as a representative sample of the overall population of FWW projects, but it does give an indication of different ways in which HLF's funding had enhanced the capacity of organisations to deliver heritage projects, even if none of the case study examples were 'new' to heritage. 


\section{Conclusions}

This final chapter summarises key conclusions from the first year of the evaluation of HLF's FWW Centenary activity. First it returns to the four assumptions the evaluators put forward as underpinning the Centenary activity and considers whether the evidence supports them, before summarising key successes and challenges faced and then outlining next steps for the evaluation.

\subsection{Examining the theory of change}

Chapter 2 outlined a number of assumptions made by the evaluators that underpinned a 'theory of change' for the Centenary activity. These were:

- Funding will lead to outcomes captured by HLF's outcome areas (and other possible additional or wider outcomes) and meet HLF's FWW Centenary aims.

- $\quad$ Outcomes would not be achieved (or to a lesser extent) without funding.

- There is particular value in funding FWW activities at this time.

- Promoting FWW activities will catalyse heritage activity more generally.

There is some evidence to support each of these assumptions. The central issue regards the role of grant funding in producing outcomes: the data presented above clearly support this. Second, there is also clear evidence that the HLF's funding is producing added value: that is, outcomes achieved are above and beyond those that would be achieved without HLF funding. There is little evidence of displacement taking place (for instance, projects choosing to do a FWW project instead of something else simply because the money is available). Third, the level of demand for FWW activities shows that there is value both in funding FWW activities at this time and it is likely that this also acts as a means of catalysing activity on heritage, although it is too early to say definitively the extent of this.

\subsection{Key successes}

The first year of the evaluation of the HLF's FWW Centenary activity has highlighted a number of key successes, as follows:

- demand for funding has been overwhelming, with the original $£ 6$ million FWW: Then and Now funding earmarked for the whole Centenary period allocated by the end of 2014, and over 1,000 projects receiving grants by April 2015

- this has led to significant levels of activity at the local level, being led by community organisations. This is important in itself and is a significant indicator of HLF's role of empowering local people and places. 
- a large number of people have engaged with projects, including significant numbers of volunteers, who have been central to the delivery of many projects and brought significant added value.

- HLF funding is having a clear impact on the capacity of organisations to deliver projects and there is also some evidence of impact on longer-term capacity.

- as a suite of activity, there is evidence of outcomes across almost all outcome areas, although this inevitably varies across individual projects (and indeed individual projects are not expected to achieve outcomes across all outcome areas). People outcomes are particularly well evidenced, particularly on learning about heritage.

- there is also evidence of progress against each of the five aims considered by this evaluation, and in line with evidence on outcomes, the most clearly realised of the five aims is centred on learning about the FWW.

\subsection{Key Challenges}

Despite a largely positive set of findings from the first year of the evaluation, a number of challenges were also raised, including the following, categorised below as challenges for projects, for HLF and for the evaluation:

\section{Challenges for projects}

- $\quad$ based on the emergent evidence above there is a challenge for projects to engage with a wider range of people. For instance, engaging a range of ethnic groups is a challenge (although the evidence is inconclusive at this stage). This requires further exploration in Year 2 of the evaluation.

- $\quad$ there might also be more to be done to engage young people in the 18-25 age group.

- projects are working well to engage with other organisations within their geographic communities as shown in the case studies, but in order to broaden the reach of projects, more might be done to engage with other Centenary projects (although this does require further investigation in Year 2 of the evaluation).

\section{Challenges for HLF}

- $\quad$ projects are engaging with a wide range of different perspectives on the FWW, but there is a concentration of local history projects, particularly in relation to war memorials (as explored in Sections 3 and 4). This can be an important hook for engaging people on broader issues relating to the FWW, but could consider whether they could do more to encourage applications that seek to approach the FWW from different perspectives.

- HLF might want to work to encourage applicants/projects to consider how they will engage with young people and widen access to heritage more generally

- following on from the challenge for projects to engage more with other FWW Centenary activity, there is a challenge for HLF to help enable this, and relatedly - to work with the AHRC to increase the extent to which Engagement Centres are supporting projects.

\section{Challenges for the evaluation}

The key challenge for the evaluation over the next year is to build on the existing dataset so that more robust conclusions can be drawn. Early survey response rates 
suggest that by the end of year two we can expect to have much larger Participant and Grant Recipient survey datasets to draw from. Beyond this general challenge are a number of specific areas that the evaluation will aim to improve and/or extend its coverage. These include:

- incorporation of additional lines of enquiry in surveys and case studies on better managing heritage

- $\quad$ seeking further detail from projects on the extent to which they have engaged young people in a variety of different organisational contexts: that is, beyond engagement with young people in schools. This might include asking about efforts to engage young people between the age of 18 and 25

- further exploration of the geography of FWW Centenary projects and activities, in terms of the types of places and areas covered by activities.

- delving further into the nature and value of projects' engagement with AHRC and other large institutional FWW partners.

- the impact of HLF funding on organisations' finances. 


\section{Appendix 1: Case study summaries}

\section{Our World War One}

Brierfield's 'Our World War One' project was funded through the First World War: Then and Now grant stream. The project involved a research project led by young people from the local secondary school, which included a range of activities aimed to produce heritage, individual and community outcomes.

The project provided an excellent example of how small projects can achieve a wide range of outcomes, in particular community outcomes, which can sometimes be hard to evidence. The project had been very successful in bringing together different population groups in the local area through a focus on the role of the Indian Army in the First World War.

\section{Making a difference}

How the project achieved outcomes for heritage:

- heritage was better interpreted/explained through: installation of a plaque in memory of the Indian Army at the Brierfield Cenotaph; employing an artist to produce a set of 'artist's minutes' ; working with a historian from the County Council to present artefacts from the Indian army; using online media such as the project blog, facebook, twitter and Historypin

- heritage was identified/recorded by researching relatives of local people; and uncover links between Indian Army regiments and local residents

How the project achieved outcomes for people:

- $\quad$ all those involved in the project had developed some new skills, and the five young people involved had been 'transformed' by their involvement

- everybody involved in the project had significantly increased their knowledge and understanding about the FWW

- the participants were able to point to changes in both attitudes and actions that they have taken as a result, in particular in understanding the 'reality' of war and its trivialisation through media representations (especially computer games)

- every person involved in the project reported having greatly enjoyed their participation in the project, and there was a much deeper sense of emotional enrichment that participants had gained from participation.

- a range of people had volunteered time to the project, including librarians, members of the RBL and the historian from the County Council.

How the project achieved outcomes for communities:

- $\quad$ each of the young people involved were 'new' to heritage in general and in the specific instance of the FWW war. It is difficult to see how they would have become engaged in these issues if the project had not taken place. 
- the project was a fantastic example of engaging with different ethnic and religious groups and promoting community cohesion through its outreach work with mosques and churches, and holding events for both White British and Asian communities to commemorate the FWW Centenary

- $\quad$ there was a feeling that - in a small way - the project had made a difference to the local area. It was starting to change perceptions about the area, and break down some barriers between different population groups.

\section{Lessons learnt}

The main success of the project has been the development of the young people participating in the project. The main challenge for the project was the relationship with the local school (where the participants were students), which had been difficult at times. 


\section{Flintshire War Memorials}

'Flintshire War Memorials' is a one-year project, the aim of which is to research the stories of those individuals named on war memorials and tell their stories on a website. The project is volunteer-led, and involves 24 volunteers undertaking research on different memorials, and writing narrative for the website for which they are supported with a range of training opportunities.

HLF funding has paid for training and IT equipment needed in order to develop the website. It has also funded research training for volunteer researchers. As well as the work surrounding the development of the website, this project also involves talks and presentations to a range of community groups, interest groups and schools in the Flintshire area.

HLF funding has enabled the project to grow at a much faster rate, has drawn more people in and turned it into a community project. It has enabled support to be given to many more volunteers, improving the level of training and support provided. It has also enabled the group to purchase equipment for giving talks and presentations.

Flintshire War Memorials has:

- Produced a website which tells the stories of service personnel from Flintshire that died in WW1

- Trained 24 volunteer researchers

- Conducted over 20 talks and presentations to local community groups and schools

- Engaged in partnerships with local schools, supporting their WW1 memorial projects via the web resource. This project has also worked with another WW1 memorial project, sharing information and skills.

- Held a celebration event

\section{Making a difference}

How the project achieved outcomes for heritage:

Collecting and recording individual stories of those listed on war memorials, leading to a different aspect of heritage being identified and recorded. This has involved researching individual stories, but also wider family and community stories. All this work has culminated in the production of a website which is growing all the time. The project has also shared these heritage stories with others via work with schools and talks / presentations. In addition to the website and talks, the research has plugged gaps which exist in this collection to be filled.

\section{How the project achieved outcomes for people:}

Skills:A central outcome for people has been the skills that the project leads have developed, including developed, including the development and maintenance of the website, presentation/public speaking skill, training and supporting volunteers. The volunteers have also developed research and IT skills, as well as confidence to be involved in more projects in the future.

Learning: Project leads, volunteer researchers and stakeholders referred to the amount of learning the project has facilitated. People have learnt about WW1, but also about individuals who served in WW1 and the context surrounding their involvement (such as the history of different regiments), and the communities 'left behind'. The development of the website will continue to share this learning into the future. 
"Last year they came to school, and gave presentations to pupils, and also gave them advice about how to contribute towards the website, and also gave me valuable advice really about how to research different ex-soldiers in the area. So really, if it wasn't for [the project leads] I don't think the project [at the school] would have started. Because they've found so many things, and they've also been so helpful, giving advice and everything" (Stakeholder, Flintshire War Memorials)

Attitudes and/or behaviour: The learning enabled through this project has given people a very different perspective, and thus has challenged some to think differently about the conflict.

Enjoyment: The interviews with volunteers and stakeholders conveyed the extent to which those involved have enjoyed the project. The volunteers referred to their attachment to the project, and the degree of ownership they had over their piece of research. Those who had been involved in the project, either through attending talks or working in partnership (such as the schools) praised the project very highly.

\section{Lessons learnt}

The level of work required to support a large team of volunteers: the project leads talked about the extremely positive experience they have had of supporting the volunteer researchers, and talked about the amount they had learnt in terms of the work involved in providing good support.

Managing a funded project: the project has been very successful, and the project leads suggested that it would have been useful to have a greater degree of flexibility with the funding, particularly in terms of allowing it to be carried-over into the next financial year, thus enabling some activities to go on beyond the first year. 


\section{Somerset Remembers the First World War}

Somerset Remembers is a project with a number of strands, which aim to explore the experiences and stories of communities in Somerset during WW1. It has developed a large scale exhibition and a touring exhibition which visits libraries, museums and other venues. It has also produced digital outputs, such as Community Archives, which is a digital platform whereby people can upload content relating to Somerset during WW1. A project officer was recruited specifically to develop, organise and oversee the programme of activities and events, and volunteers have played a key role in archive research, exhibition invigilation and tours. A mixture of formal and informal learning opportunities has taken place, ranging from film nights to school activities.

\section{Making a difference}

How the project achieved outcomes for heritage:

- The exhibition collected and displayed a range of stories about how people within Somerset contributed to WW1

- A new approach was taken to the interpretation and explanation of heritage, whereby story objects were incorporated into the exhibition alongside archival sources

- The creation of The Somerset Remembers Online Community Archive, which will have a life beyond the project

How the project achieved outcomes for people:

- Enabled learning about WW1 from the perspective of communities within Somerset, and in particular learning about individual stories and experiences

- Volunteer researchers have learned about the history of Somerset during WW1

- Many volunteers from this project have gone on to volunteer on subsequent projects within the museum

- Employees of the Heritage Centre have developed and consolidated skills and experience, increasing the capacity of the centre

How the project achieved outcomes for communities:

- More people have engaged with heritage as a result of the project

- The project has increased opportunities for schools to become involved through visits and use of the project resources

- The project has supported the development of a strong network of groups and organisations

- $\quad$ The long-term sustainability of the museum and Heritage Centre were attributed to HLF funding, as the organisations had built positive reputations as a result of this project

\section{Lessons learnt}

This project has encouraged the project lead to consider focusing on fewer activities, rather than over-committing and spreading resources too thinly.

The project would, with hindsight. have liked to have engaged with, and involved, the hardto-reach groups in the activities, but this was recognised as being dependent on a greater capacity and knowledge of working with the hard to reach groups within the Somerset Heritage Centre. 


\section{Somerset Remembers the First World War}

The project, 'A War Unheard' involved a young person led approach to developing and delivering several FWW centenary activities, including an exhibition and performance. Local FWW stories were researched and developed for the script for the play, artefacts for the exhibition and for online resources. The 'local' focus of the project generated greater identification, interest and empathy in local people.

The Eden Court Theatre worked with eight young people aged 16-25 from across the Highland to form a performance company called the Eden Court Collective. In partnership with the Fort George Education team at the Highlanders' Museum, the Collective did the following:

- They researched their own family history of the First World War, and unheard stories from their local areas. This research was used to create a site specific performance for a public audience at Fort George in September 2014.

- Digital and photographic evidence of their research was used to create an exhibition which was displayed at Fort George and Eden Court from September 2014 to May 2015.

- Information was digitised and uploaded to the Highlanders Museum website to be used as an online resource for schools and the public.

- A film was produced of the performance and a documentary about the making of the project.

\section{Making a difference}

\section{How the project achieved outcomes for heritage}

The exhibition and new on-line resources contributed to outcomes for heritage in a number of ways:

- By providing new case studies of local stories of the war that didn't exist in an accessible format.

- By providing local young people with the opportunity to engage with their own heritage in a new and creative way and sharing it with the wider Highland community

\section{How the project achieved outcomes for people}

A number of outcomes were achieved for the young people involved in the project, including:

- The development of skills in acting, research, using digital media, creating exhibitions, devising theatre, communication, confidence, leadership and teamwork.

- A better knowledge, and understanding of their heritage, which was shared with others.

- An enjoyable experience that was shared with others.

\section{How the project achieved outcomes for communities}

The Highland communities, including new young people, attending the performance, accessing the on-line resources, seeing the exhibition and/or the documentary and were able to engage with local heritage that they might not have otherwise have engaged with. The first time outdoor performance attracted an audience of over two hundred people. Some of them expressed their enjoyment of the event on Facebook, providing, 'really good 
feedback'. Notably, new local visitors, and local people who hadn't visited the museum for some time were drawn to the FWW activities:

Attendees were not only the usual theatre goers or family members of the cast, but people from all age ranges; the young and old.

Feedback gathered from young people was documented in a film, and the response from the ex-military attendees was also very positive.

The success of the project put Eden Court on the map and positively raised the profile of the organisation as a whole. The project lead commented, 'we do great stuff a lot and a lot of people are unaware of it.....the gravity of the project was able to bring that home because it was such a good tag for it to have - the heritage.'

\section{Lessons learnt}

Some learning was highlighted around the lack of lead in time from initially securing the funding to delivering the FWW activities. The museum's Education Outreach Officer explained that the timescales were tight

Also, the formal recognition and training of volunteers was felt to be a missed opportunity, particularly in terms of recording how individuals contributed to the project and their level of time and knowledge invested in the project. 


\section{On The Brink: Politics of Conflict 1914-1916}

'On the Brink' is a three-year project working across a partnership of 8 local authority areas across Mid and East Antrim, which explores the impact of the Battle of the Somme and the Easter Rising. The project aims to demonstrate the links between two key conflicts - the Battle of the Somme and the Easter Rising - which resonate for people within Northern Ireland, and encourages people from all communities to understand their shared histories.

'On the Brink' aims to support learning through a variety of means, including exhibitions, workshops and tours. The volunteer tour guide training is a particular focus of the project, which will enable volunteers to lead tours around local WW1 memorial sites. The project also enables broader participation through wider engagement opportunities raising awareness and telling stories from all aspects of the conflicts.

\section{Making a difference}

How the project achieved outcomes for heritage:

- The workshops and research being conducted will culminate in the collection of previously untold personal and social histories from times of conflict.

- Better quality conservation of key artefacts which are part of the 'On the Brink' exhibitions

- The project will be able to influence overarching collections policies of the institutions involved

How the project achieved outcomes for people:

- Volunteer training is a central aspect of the On the Brink project, and will result in trained volunteers leading tours around local memorial sites.

- Volunteers have had the opportunity develop knowledge and understanding about their local, national and international history in greater depth

- Volunteers have benefited socially, meeting people and building confidence.

How the project achieved outcomes for communities:

- The project has enabled local schools to get involved, via links with the curriculum and offering workshops and access to the exhibitions

- The project is supporting people from both nationalist and unionist communities to share learning and develop shared understandings about the period between 19141916

\section{Lessons learnt}

Working across 8 local authorities has presented challenges, particularly in terms of the time and resources needed to make such a partnership run smoothly. It has also been challenging to ensure that all authority areas are represented as equally as possible within the exhibitions/collections.

The project has been working to engage people from both unionist and nationalist communities, but the latter has proven to be more of a challenge, due to the geography of the project, but also because of perceptions of ownership over historical events. 


\section{Appendix 2: Case study interview profile}

Five case studies were undertaken in the first year of the evaluation. The purpose of case studies was capture in-depth qualitative data, set within the context of particular projects. While quantitative surveys give a sense of 'what' happened, case studies allow for a nuanced understanding of questions relating to 'how' things happened.

Case studies involved interviews with the project lead, mix of participants, volunteers, visitors and other stakeholders. This varied across projects depending on who was deemed most appropriate to interview in the context of each activity. A total of 34 interviews were completed. The profile of interviews is shown in Table A2.1, below

Table A2.1: Interviews completed by case study

\begin{tabular}{ll}
\hline Case study & Interview profile \\
\hline Our World War One (Brierfield) & $2 \times$ project leads \\
& $4 \times$ participants \\
& $1 \times$ volunteer \\
On the Brink (Ballymena) & $1 \times$ project lead \\
& $3 \times$ volunteers \\
Flintshire War Memorials & $1 \times$ project lead \\
& $5 \times$ volunteers \\
Somerset Remembers & $1 \times$ stakeholder \\
& $1 \times$ project lead \\
& $5 \times$ visitors \\
& $1 \times$ volunteer \\
A War Unheard (Inverness) & $1 \times$ stakeholder \\
& $2 \times$ project leads \\
& $5 \times$ participants \\
& $1 \times$ volunteer \\
\hline
\end{tabular}




\section{Sheffield Hallam University}

Evaluation of Heritage Lottery Fund's First World War Centenary Activity: Year 1 report

BASHIR, Nadia <http://orcid.org/0000-0002-1384-4849>, BENNETT, Ellen

<http://orcid.org/0000-0003-3271-8757>, DAYSON, Christopher <http://orcid.org/0000-

0003-2402-1183>, EADSON, William <http://orcid.org/0000-0002-2158-7205> and

SANDERSON, Elizabeth <http://orcid.org/0000-0003-1423-1670>

Available from the Sheffield Hallam University Research Archive (SHURA) at:

http://shura.shu.ac.uk/26883/

\section{Copyright and re-use policy}

Please visit http://shura.shu.ac.uk/26883/ and http://shura.shu.ac.uk/information.html for further details about copyright and re-use permissions. 